\title{
Acceptance sampling for attributes via hypothesis testing and the hypergeometric distribution
}

\author{
Robert Wayne Samohyl ${ }^{1}$ (D)
}

Received: 13 March 2017/ Accepted: 13 September 2017/Published online: 7 October 2017

(C) The Author(s) 2017. This article is an open access publication

\begin{abstract}
This paper questions some aspects of attribute acceptance sampling in light of the original concepts of hypothesis testing from Neyman and Pearson (NP). Attribute acceptance sampling in industry, as developed by Dodge and Romig (DR), generally follows the international standards of ISO 2859, and similarly the Brazilian standards NBR 5425 to NBR 5427 and the United States Standards ANSI/ASQC Z1.4. The paper evaluates and
\end{abstract}

When acceptance sampling is presented as a collection of tables in step-by-step recipes, practitioners can learn enough in a few hours to set up sampling plans, and filter out some of the non-conforming product in large lots. This, however, is not enough to negotiate agreements over the long run especially among international businesses. This review of acceptance sampling results from a consultant's need to go beyond the table-and-recipe stage of introductory training, and advance to a level of understanding compatible with the formation of international contracts. We dedicate this work to all those practitioners (especially Elton Thiesen and Carlos Reich) who successfully (and quickly) acquired sufficient knowledge of sampling standards to apply sampling plans on the shop floor but confronted a consultant/professor whose toolkit lacked an intuitive approach compatible with the shop floor environment. Thanks to Jan van Lohuizen, Armin Koenig and Osiris Turnes who carefully read the first rough draft and offered insightful practical comments. Special thanks to Galit Shmueli who kindly encouraged this project and made some initial corrections in personal correspondence. If merit exists, it belongs to everyone; errors are mine.

Robert Wayne Samohyl retired from the Núcleo de Normalização e Qualimetria (NNQ).

Robert Wayne Samohyl

robert.samohyl@ufsc.br

1 Federal University of Santa Catarina, Florianópolis, Brazil extends the area of acceptance sampling in two directions. First, by suggesting the use of the hypergeometric distribution to calculate the parameters of sampling plans avoiding the unnecessary use of approximations such as the binomial or Poisson distributions. We show that, under usual conditions, discrepancies can be large. The conclusion is that the hypergeometric distribution, ubiquitously available in commonly used software, is more appropriate than other distributions for acceptance sampling. Second, and more importantly, we elaborate the theory of acceptance sampling in terms of hypothesis testing rigorously following the original concepts of NP. By offering a common theoretical structure, hypothesis testing from NP can produce a better understanding of applications even beyond the usual areas of industry and commerce such as public health and political polling. With the new procedures, both sample size and sample error can be reduced. What is unclear in traditional acceptance sampling is the necessity of linking the acceptable quality limit (AQL) exclusively to the producer and the lot quality percent defective (LTPD) exclusively to the consumer. In reality, the consumer should also be preoccupied with a value of AQL, as should the producer with LTPD. Furthermore, we can also question why type I error is always uniquely associated with the producer as producer risk, and likewise, the same question arises with consumer risk which is necessarily associated with type II error. The resolution of these questions is new to the literature. The article presents $\mathrm{R}$ code throughout.

Keywords Acceptance sampling - Lot quality assurance sampling (LQAS) · Hypergeometric · Operating characteristic curve $(\mathrm{OCC}) \cdot$ Receiver operating characteristic (ROC) Curve · Hypothesis test - R CRAN 


\section{Introduction}

In commerce, any negotiation puts buyer and supplier in direct conflict. ${ }^{1}$ Although the exchange of products and services can take place either with legal contracts or as informal agreements promoting the welfare of all participants, the main characteristic of negotiation is the attempt of one adversary to gain more. Even in honest and open negotiations with a relatively free flow of well-defined objectives among all participants, there are still differences between the antagonisms of buyers and sellers. Each adversary is an independent decision maker at least in theory, capable of assuming responsibility for her own decisions. In the commerce of large lots of standardized goods, statistical modeling and the concepts of probability can distinguish between different points of view, recognizing and revealing the conflicts inherent in negotiations. Consequently, to ensure the quality of large lots, each party may require different contractual sampling plans which specify lot size $(N)$, sample size $(n)$ and the maximum number of defective parts $(c)$ in the sample that still allows for lot acceptance, the formal symbols are $\operatorname{PL}(N, n, c)$.

The main objective of this paper is to discuss the relationship between acceptance sampling and formal hypothesis tests as developed by NP. Considering that the pioneering work of Dodge and Romig (DR) (1929) in acceptance sampling, which has survived decades of academic debate and practice, arrived before the formalization of hypothesis testing by NP, the question is why bring hypothesis testing into the discussion at all. Throughout the rest of this paper, we will attempt to show that, if used appropriately, hypothesis testing offers a more logically complete structure to decision-making and therefore to better decisions.

It is common in the literature (for example, Shmueli 2011; Hund 2014), but not in the original pioneering work of DR, to associate consumer and producer ${ }^{2}$ risk with the concepts of the probability of type II and type I error, respectively. In our approach, we shall go further and develop the generalization that both consumer and producer feel the cost of both errors. In other words, we shall explicitly allow for two type I errors and two type II errors depending on the perspective of the consumer or the

\footnotetext{
$\overline{1}$ The specific area of applied statistics elaborated here possesses at least three different names. In industrial settings and in this article, the name is Acceptance Sampling. When DR first introduced this statistical application, the name was Inspection Sampling. In medicine and public health, the name is Lot Quality Assurance Sampling (LQAS). See, for example, Biedron et al. (2010). A very popular textbook discussion is Shmueli (2011), Schilling and Neubauer (2009) and NIST/SEMATECH (2012).

${ }^{2}$ Consumer and producer are the names used in the original work of DR. Sometimes we will use similar terms like buyer and seller without causing confusion.
}

producer. We will show that the decision-making process may be compromised by the commonly used simplification that type I error is felt only by the producer and in like manner type II error is inclusive only to the consumer. Hypothesis testing from NP, by offering a common theoretical structure, can produce a better understanding of the application of sampling procedures and their results. ${ }^{3}$ In a series of examples, we show that measures of risk will be more reliable and risk itself lowered.

Deming (1986) was opposed to acceptance sampling. He argued that inspection by sampling leads to the erroneous acceptance of bad product as a natural and inevitable result of any commercial process, which in turn leads to the abandonment of continuous process improvement at the heart of the organization. Deming's position that inspection should be either abandoned altogether or applied with $100 \%$ intensity has been debated in the literature (see Chyu and $\mathrm{Yu}$ 2006, for review and a Bayesian approach to the question), and his position is supported by some. Even though acceptance sampling is only a simple counting exercise with no analysis for uncovering the causes of nonconforming quality, ${ }^{4}$ our position is that acceptance sampling should be an integral part of the commercial-industrial process and, even when perfect confidence reigns between buyer and seller, but sampling itself should never be abandoned. Deming (1975), however, was very much in accord with statistical studies by random sampling that are restricted to inferring well-defined characteristics of large populations, just not as a procedure for continuous quality improvement.

In the next section, we discuss traditional acceptance sampling emphasizing those concepts modified in the rest of the text. Sections "Lot tolerance percent defective (LTPD) in consumer risk" and "Acceptable quality limit (AQL) in producer risk" will present the traditional relationships between AQL and producer risk, and LTPD and consumer risk. Section "A unique sampling plan for both parties-DR tradition" closes the discussion of traditional acceptance sampling offering the possibilities of constructing sampling plans that are unique for both producer and consumer. In section "Acceptance sampling via hypothesis tests", we will lay out our interpretation of NP hypothesis testing and its connection to acceptance sampling. The next two sections will attempt a synthesis of basic concepts in NP hypothesis testing and acceptance sampling. We then propose new procedures for the solution to unique sampling plans that simultaneously satisfy producer and consumer. Finally, the last two sections present

\footnotetext{
3 The author has applied the basic ideas in this article to the polling of public opinion and public health (Samohyl 2015, 2016).

${ }^{4}$ See Samohyl (2013) for a causal analysis of quality via logistic regression.
} 
conclusions and ideas for future work in the area. A series of appendices offer review material for statistical concepts frequently used in acceptance sampling, including $R$ snippets that give a brief description of the $\mathrm{R}$ code used in figures and tables.

\section{Traditional acceptance sampling}

Considering that the pioneering work of DR comes earlier than the formalization of hypothesis testing by NP, the question is why acceptance sampling should integrate hypothesis testing at all. We will show that hypothesis testing can offer a common structure that generalizes and clarifies some issues in the application of acceptance sampling.

DR formally introduced inspection sampling in 1929 and in fact only from the viewpoint of the consumer. The priority given to the consumer will be an important ingredient for the discussion of hypothesis testing in this paper. They mention producer risk only marginally. In 1944, they emphasize even more clearly their position that consumer risk is their first priority (Dodge and Romig 1944).

The first requirement for the method will, therefore, be in the form of a definite assurance against passing any unsatisfactory lot that is submitted for inspection. [...] For the first requirement, there must be specified at the outset a value for the lot tolerance percent defective (LTPD) as well as a limit to the probability of accepting any submitted lot of unsatisfactory quality. The latter has, for convenience, been termed the Consumer's Risk....

Both consumer and producer are concerned with the quality of the lot measured by the percentage $(p=X / N)$ of defective items. Values of $p$ close to zero indicate that the lot is high quality. In traditional acceptance sampling, it is natural to assume that the producer requires a relatively low maximum value for $p$ to guarantee that the lot is, in fact, acceptable to the consumer. The producer calls this limiting value for $p$ the acceptable quality level (AQL). Even though management and business strategy determine the value of AQL, it should reflect the actual value of quality reached by the producer. A value of AQL lower than the dictates of the production line will lead to sequential rejections. On the other hand, the consumer in question will allow for a limiting value of $p$ that is a maximum value for defining the defective rate tolerable to the consumer who calls this value the LTPD. ${ }^{5}$ Any value of

\footnotetext{
5 Also called limiting quality and consumer's risk quality in ISO (1999, 1985).
}

$p$ greater than LTPD signifies that the consumer will reject the lot as low quality. Both producer and consumer know that AQL should be substantially lower than LTPD; this signifies that lots have relatively high quality when they leave the producer and avoid rejection by the buyer.

The classification rule in traditional acceptance sampling is relatively simple: a lot is acceptable if in a sample of size $n$ the number of defective parts $x$ is less than or equal to a predetermined cutoff value $c$. The inequality $x \leq c$ identifying a high quality sample signifies that it is very likely that the lot also possesses an acceptable level of quality. On the other hand, if $x$ is greater than $c(x>c)$, identifying a lowquality sample, then it is likely that the lot is also of low quality. The practice of acceptance sampling determines the values of $c$ and $n$ that reduce to an acceptable level the probability of error. In other words, the intention of acceptance sampling is to minimize the probability of wrongly classifying the lot. Equation (1) represents the conditional probability of the sample indicating unacceptable low quality $x>c$ when, in fact, the lot is high quality $p \leq \mathrm{AQL}$, a false positive $(F P) .{ }^{6}$ The cost of rejecting good lots falls heavily on the producer, more than the consumer.

$$
\begin{aligned}
P(x>c / p \leq \mathrm{AQL}) & =P(\mathrm{FP}) \\
& =\text { probability of a false positive }(\mathrm{FP})
\end{aligned}
$$

The equation illustrates that the frequency of FPs depends on the chosen values of $c$ and AQL. For example, if they were chosen to result in $P(F P)=5 \%$, then, in the universe of high-quality lots, $5 \%$ of all samples would indicate in error that the lot was unacceptable. DR label Eq. (1) as producer risk. The producer who rejects a good product is creating a problem that in fact does not exist, perhaps even stopping the assembly line to find solutions to difficulties only imagined. Traditional acceptance sampling refers to Eq. (1), the probability of type 1 error, as $\alpha$. We emphasize that DR never associated producer and consumer risk to type I and type II error.

When the sample includes a small number of defective items $(x \leq c)$, this indicates to the buyer that the lot is high quality. Equation (2) represents the conditional probability of the sample indicating high quality when, in fact, the lot is unacceptable ( $p>$ LTPD). This condition represents a false negative $(F N)$.

$$
\begin{aligned}
P(x \leq c / p>\mathrm{LTPD}) & =P(\mathrm{FN}) \\
& =\text { probability of a false negative }(\mathrm{FN})
\end{aligned}
$$

\footnotetext{
${ }^{6}$ The use of the concepts of positive and negative are common in the medical and data science literature, for instance, Provost and Fawcett (2013, chap. 7). Sensitivity of a test to recognize true positives (TP/ (all positives)). Specificity is the capacity to recognize true negatives (TN/(all negatives)).
} 
DR labeled Eq. (2) as consumer risk since acquiring bad product would harm assembly lines or retail with lowquality inputs and merchandise. In traditional acceptance sampling, the probability of type 2 error (Eq. (2)) takes the name of $\beta$. In the application of acceptance sampling, the producer and consumer predetermine the acceptable values for $P(\mathrm{FN})$ and $P(\mathrm{FP})$ along with LTPD and AQL. The solution for $n$ and $c$ called a sampling plan (or sample design) $P L(n, c)$ is mathematically determined from the binomial or Poisson distribution. All of this information is summarized Table 1.

The application of acceptance sampling procedures fall into three simple steps:

1. Determine the values for the size of the sample $n$ and the cutoff limit $c$.

2. Draw the sample and count the number of defective items $c$ in it

3. a. If $x \leq c$ then accept the lot as likely high quality, but this may be wrong for $\beta$ percent of bad lots.

b. If $x>c$ then reject the lot as likely low unacceptable quality, but this may be wrong for $\alpha$ percent of good lots.

Later on, our considerations on hypothesis testing will require modifications in the above steps. Appendix "Operating characteristic curve (OCC)" presents the operating characteristic curve (OCC). The curve is a standard statistical tool for understanding and constructing sampling plans and appears several times in this article.

\section{Lot tolerance percent defective (LTPD) in consumer risk}

The consumer defines the LTPD as the maximum acceptable rate of poor quality. The sampling plan, if well thought out, possesses values for $n$ and $c$ that indicate little chance of acceptance if $p$ is greater than the LTPD tolerated by the consumer. Specifically, this means that the probability of error $P(x \leq c / p \geq \mathrm{LTPD})=\beta$ is very small. In other words, the consumer protects herself against poor quality by choosing an adequate sampling plan that keeps her risk at a low and tolerable level for undesirable levels of $p$.

In Fig. 1 the sampling plan is $P L(3000,200,0)$, remembering that it is generally beneficial to the buyer to have a very small $c$. In this example, LTPD is $1 \%$. With $p$ equal to $1 \%$ or greater (quality worse), there is a probability of still accepting the lot equal to 0.125 or less. Depending upon the necessities and market power of the buyer, consumer risk of less than $12.5 \%$ may be required. It is important to emphasize that the sampling plans analyzed in this section follow the cumulative hypergeometric distribution (Appendix "Hypergeometric distribution").

Along the OCC, the pair of values LTPD and P(LTPD) signifies a single point. There are several configurations of $P L(N, n, c)$ compatible with a given pair of values for LTPD, $P$ (LTPD), each configuration producing different shapes for the OCC. The choice of configuration, in practice, is not as free as it seems. Technology and the commercial terms of the negotiation usually impose lot size $N$. The value of $c$ usually does not flee too far from zero. In the end, only sample size $n$ remains unknown. We discuss this question further in what follows.

Table 2 shows new calculations for consumer sampling plans defined by $P($ LTPD) and LTPD. The columns labeled letter, $N$, $n$, and $c$ are common to most sampling standards. Shmueli (2011) uses ANSI/ASQC Z1.4 and ISO 2859 (1999, 1985) extensively. Note that in the table adequate sampling plans for the consumer are not abundant. There are few plans that produce a risk factor less than $10 \%$. They appear mostly in the last three lines of the table. Table 3 produces comparable results for producer risk. This exercise in comparing consumer and producer risk serves to demonstrate the difficulty for two bargaining parties to find one unique plan that would satisfy the minimum risk requirements of both simultaneously. We will return to this topic after the discussion of producer risk.

\section{Acceptable quality limit (AQL) in producer risk}

Producer error comes from the idea that the producer suffers more from the rejection of good lots than the acceptance of bad ones. To calculate producer risk, the producer
Table 1 Traditional lot classification in acceptance sampling with sample results compared to the real state

\begin{tabular}{llll}
\hline Real states of population & Sample results & \\
\cline { 2 - 3 } & $x \leq c$ & $x>c$ & \\
\hline$p \leq \mathrm{AQL}$ & $P(x \leq c / p \leq \mathrm{AQL})$ & $P(x>c / p \leq \mathrm{AQL})=\alpha$ & $\sum P=1$ \\
& $P(\mathrm{TN})$ & $P(\mathrm{FP})$ error $(\mathrm{Eq} .1)$ & \\
$p \geq$ LTPD & $P(x \leq c / p \geq \mathrm{LTPD})=\beta$ & $P(x>c / p \geq \mathrm{LTPD})=1-\beta$ & $\sum P=1$ \\
& $P(\mathrm{FN})$ error $(\mathrm{Eq} .2)$ & $P(\mathrm{TP})$ & \\
\hline
\end{tabular}

$T N$ true negative, $T P$ true positive, $F P$ false positive, $F N$ false negative 
Fig. 1 Hypergeometric sampling plan as OCC for $P L(3000,200,0)$ and $\mathrm{LTPD}=0.01$

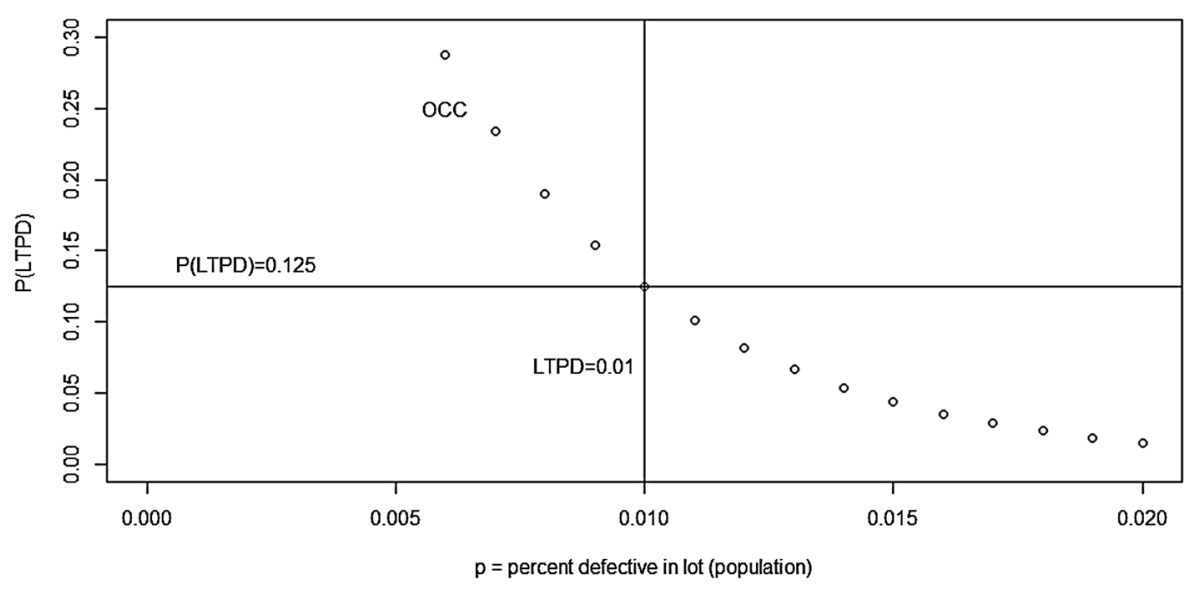

Table 2 Traditional consumer sampling plans and consumer risk with the hypergeometric distribution

\begin{tabular}{|c|c|c|c|c|c|c|c|c|c|c|}
\hline \multirow[t]{2}{*}{ Letter } & \multirow[t]{2}{*}{$N$} & \multicolumn{2}{|c|}{$\mathrm{LTPD}=0.65 \%$} & \multirow[t]{2}{*}{ Consumer risk } & \multicolumn{2}{|c|}{$\mathrm{LTPD}=1.0 \%$} & \multirow[t]{2}{*}{ Consumer risk } & \multicolumn{2}{|c|}{$\mathrm{LTPD}=1.5 \%$} & \multirow[t]{2}{*}{ Consumer risk } \\
\hline & & $n$ & $c$ & & $n$ & $c$ & & $n$ & $c$ & \\
\hline $\mathrm{J}$ & 1200 & 80 & 0 & .575 & 80 & 0 & .435 & 80 & 0 & .286 \\
\hline $\mathrm{K}$ & 1201 & 125 & 0 & .414 & 125 & 0 & .266 & 125 & 0 & .136 \\
\hline $\mathrm{K}$ & 3200 & 125 & 0 & .432 & 125 & 0 & .278 & 125 & 0 & .146 \\
\hline $\mathrm{L}$ & 3201 & 200 & 0 & .257 & 200 & 0 & .126 & 200 & 1 & .188 \\
\hline $\mathrm{L}$ & 10,000 & 200 & 0 & .268 & 200 & 0 & .131 & 200 & 1 & .194 \\
\hline M & 10,001 & 315 & 0 & .124 & 315 & 1 & .172 & 315 & 2 & .144 \\
\hline M & 35,000 & 315 & 0 & 126 & 315 & 1 & .175 & 315 & 2 & .147 \\
\hline $\mathrm{N}$ & 35,001 & 500 & 1 & 161 & 500 & 2 & .122 & 500 & 4 & .128 \\
\hline $\mathrm{N}$ & 150,000 & 500 & 1 & .163 & 500 & 2 & .123 & 500 & 4 & .130 \\
\hline $\mathrm{P}$ & 150,001 & 800 & 2 & .107 & 800 & 4 & .098 & 800 & 7 & .087 \\
\hline $\mathrm{P}$ & 500,000 & 800 & 2 & .108 & 800 & 4 & 0.098 & 800 & 7 & .088 \\
\hline Q & $500,001+$ & 1250 & 4 & .092 & 1250 & 8 & 0.123 & 1250 & 13 & .106 \\
\hline
\end{tabular}

Table 3 Traditional producer sampling plans and producer risk with the hypergeometric distribution; Appendix "Producer sampling plans recalculated with the hypergeometric distribution" has a complete table of producer risk

\begin{tabular}{|c|c|c|c|c|c|c|c|c|c|c|c|c|}
\hline \multirow[t]{2}{*}{ Letter } & \multirow[t]{2}{*}{$N$} & \multicolumn{2}{|c|}{$\mathrm{AQL}=0.65 \%$} & \multirow[t]{2}{*}{ Producer risk } & \multicolumn{2}{|c|}{$\mathrm{AQL}=1.0 \%$} & \multirow{2}{*}{ Producer risk } & \multicolumn{2}{|c|}{$\mathrm{AQL}=1.5 \%$} & \multirow[t]{2}{*}{ Producer risk } & \multirow[b]{2}{*}{$\mathrm{c}$} & \multirow[t]{2}{*}{ PRODUCER risk } \\
\hline & & $n$ & $c$ & & $n$ & $c$ & & $n$ & $c$ & & & \\
\hline $\mathrm{J}$ & 1200 & 80 & 0 & .425 & 80 & 0 & .565 & 80 & 0 & .714 & 5 & .001 \\
\hline $\mathrm{K}$ & 1201 & 125 & 0 & .586 & 125 & 0 & .734 & 125 & 0 & .864 & 5 & .007 \\
\hline $\mathrm{K}$ & 3200 & 125 & 0 & .568 & 125 & 0 & .722 & 125 & 0 & .854 & 5 & .010 \\
\hline $\mathrm{L}$ & 3201 & 200 & 0 & .743 & 200 & 0 & .874 & 200 & 1 & .812 & 6 & .028 \\
\hline $\mathrm{L}$ & 10,000 & 200 & 0 & .732 & 200 & 0 & .869 & 200 & 1 & .806 & 6 & .031 \\
\hline M & 10,001 & 315 & 0 & .876 & 315 & 1 & .828 & 315 & 2 & .856 & 7 & .101 \\
\hline M & 35,000 & 315 & 0 & .874 & 315 & 1 & .825 & 315 & 2 & .853 & 7 & .104 \\
\hline $\mathrm{N}$ & 35,001 & 500 & 1 & .839 & 500 & 2 & .878 & 500 & 4 & .872 & 9 & .221 \\
\hline $\mathrm{N}$ & 150,000 & 500 & 1 & .837 & 500 & 2 & .877 & 500 & 4 & .870 & 9 & .222 \\
\hline $\mathrm{P}$ & 150,001 & 800 & 2 & .893 & 800 & 4 & .902 & 800 & 7 & .913 & 12 & .424 \\
\hline $\mathrm{P}$ & 500,000 & 800 & 2 & .892 & 800 & 4 & .902 & 800 & 7 & .912 & 12 & .424 \\
\hline Q & $500,001+$ & 1250 & 4 & .906 & 1250 & 8 & .877 & 1250 & 13 & .894 & 18 & .508 \\
\hline
\end{tabular}


must decide upon the value of AQL. If $p \leq \mathrm{AQL}$, then the batch is defined as good, and likewise, if $p>\mathrm{AQL}$ lots are considered non-compliant. Well-chosen AQL and corresponding sampling plans reduce producer risk and therefore increase the probability of not rejecting good lots. The producer should offer items that bring high levels of satisfaction to the consumer and consequently renewed contracts. This means that AQL should always be less than LTPD.

In Fig. 2, the sampling plan is $P L(3000,10,0)$, and AQL is $0.5 \%$. For $p$ equal to $0.5 \%$, the probability of accepting the lot is equal to $P(\mathrm{AQL})=0.951$. Since the sum of the probabilities of accepting the good lot and rejecting the good lot is equal to unity (see the definition of $\alpha$ in Table 1), the probability of rejection of the good lot is $0.049(=1-0.951)$. If $p$ is less than the AQL of $0.5 \%$, high quality is present; the producer is more likely to accept the lot. Remember that the probability of rejecting good lots is producer risk. In Fig. 2, the horizontal line $P(\mathrm{AQL})$ divides the vertical axis at 0.951 , and the part above that point up to the limit of one is the producer risk 0.049 . In industry, a producer risk $1-P(\mathrm{AQL})$ below $5 \%$ is very attractive and usual for acceptance sampling.

The pair $\mathrm{AQL}$ and $P(\mathrm{AQL})$ may correspond to several sampling plans and, consequently, several OCCs. In the next section, we will investigate the difficulties in finding a single sampling plan that would allow for both producer and consumer to possess their own distinct values of AQL and LTPD, and the risk factors $P($ LTPD) and $\{1-P(\mathrm{AQL})\}$ all for one unique sampling plan, $P L(N, n$, $c)$. If such a plan exists, one unique inspection somewhere between producer and consumer would satisfy all parties and inspection costs reduced.

Table 3 has the same sampling plans as Table 2 but from the point of view of the producer. The table has an additional set of sampling plans in the last columns where $c$ has comparatively larger values than $c$ in the other columns. Only in the last column of the table are there sampling plans that would satisfy the requirements of the producer. Plans where $c=5$ or 6 have risk factors that are less than $10 \%$, even though in practice a risk limit of $5 \%$ for the producer is much more common.

Recognizing that the points of view of the producer or consumer come from different perspectives, the value chosen for $c$ is of pivotal importance. The producer will want a $c$ that is relatively large, admitting the possibility of accepting bad lots so that there is no rejection of good lots. The consumer, on the other hand, will desire a low value for $c$, consequently rejecting some good lots but better guaranteeing the acceptance of only good lots. Therefore, it will be difficult if not impossible to find values for $c$ that will serve the desires of both adversaries.

\section{A unique sampling plan for both parties-DR tradition}

A solution for a unique sampling plan for buyer and seller might be determined based on five predetermined parameters and the search for appropriate values for $n$ and $c$. The five predetermined parameters are:

LTPD e $P$ (LTPD), desired values for the consumer, AQL e $[1-P(\mathrm{AQL})]$, desired values for the producer, and

$\mathrm{N}$ lot size (same for both parties), necessary as a parameter of the hypergeometric probability function $\mathrm{H}\{\}$.

Following Eq. 6 in the appendix,
Fig. 2 Hypergeometric sampling plan with the OCC for $P L(3000,10,0)$ and $\mathrm{AQL}=0,005$

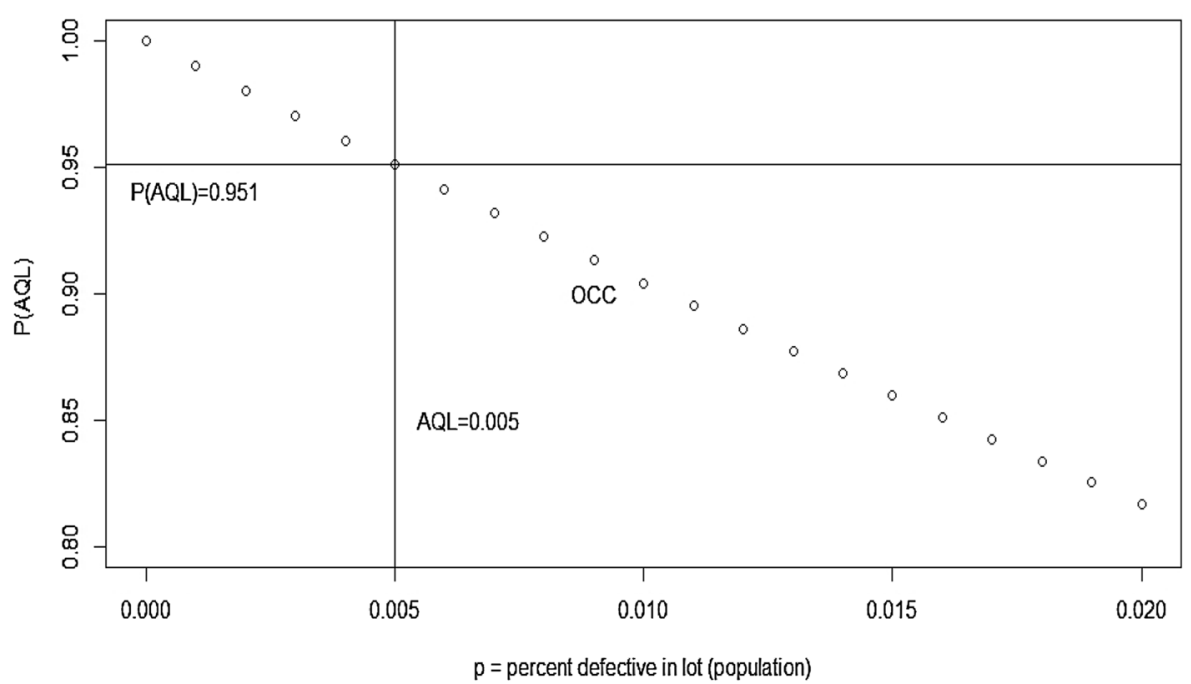




$$
\text { Consumer risk }=P(\mathrm{LTPD})=\mathrm{H}\{\mathrm{PL}(N, n, c), \mathrm{LTPD}\}
$$

$$
\begin{aligned}
\text { Producer risk } & =1-P(\mathrm{AQL}) \\
& =1-\mathrm{H}\{\operatorname{PL}(N, n, c), \mathrm{AQL}\}
\end{aligned}
$$

It is common practice in all standards for commerce and industry to work with consumer and producer risks at maximum values of either 5 or $10 \%$. The common risk percentages produce four cases illustrated in Table 4.

In case 5-5, both producer risk [ $1-P(\mathrm{AQL})]$ and consumer risk $P$ (LTPD) are 5\%. In Fig. $3 \mathrm{AQL}$ and LTPD are set at 0.005 and 0.01 , respectively. We have drawn the corresponding ROC curve (see Appendix "The receiver operating characteristics (ROC) curve") using the hypergeometric function for $c=10,11,12,13$. The plan $P L(3000,1600,11)$ satisfies the risk conditions specified by buyer and seller, that both risks be less than $5 \%$. Because of the discreteness of the probability function, consumer risk is $4.9 \%$ and producer risk is $3.2 \%$ at $c=11$. Along the ROC curve, the value of $c$ changes and accordingly the values of $\alpha$ and $\beta$. For example, the plan $P L(3000,1600,12)$ is supported by $\alpha=0.7 \%$ and $\beta=9.9 \%$. This last plan is much better for the producer and much worse for the consumer. The higher ROC curve originates from the binomial distribution with the same sampling plan; nevertheless, due to the mathematics of the binomial, consumer and supplier risks result in much larger values, greater than $10 \%$. The binomial deceives the decision makers into seeing almost double the risk where it does not exist.

Case 5-10, illustrated in Fig. 4, is the most encountered in practice: consumer risk at $10 \%$ and producer risk $5 \%$. Buyers (who are disinterested or ignorant to the disadvantages) apply sampling plans that follow these risk levels even though they are prejudicial to the buyer himself. For AQL and LTPD at 0.005 and 0.01 , respectively, the plan $P L(3000,1400,10)$ satisfies the risk conditions specified. Buyer risk is 0.098 and producer risk is 0.034 . This plan is slightly easier to apply than case 5-5, given the smaller sample $n$ and acceptance number $c$.

Case $10-5$ in Fig. 5, represents a sampling plan that pleases the buyer and demonstrates his market power by putting the seller at a disadvantage. This case is actually quite frequent when the seller is a small or medium sized

Table 4 Common risk settings for maximum permissible values for consumer and producer risk

\begin{tabular}{lcr}
\hline Risk settings & \multicolumn{2}{l}{ Consumer risk $P(\mathrm{LTPD})$} \\
\cline { 2 - 3 } & $5 \%$ & $10 \%$ \\
\hline Producer risk 1 $-P(\mathrm{AQL})$ & & \\
$5 \%$ & $5-5$ & $5-10$ \\
$10 \%$ & $10-5$ & $10-10$ \\
\hline
\end{tabular}

establishment and the buyer is a large retailing or manufacturing firm; producer risk $\left[1-\mathrm{P}\left(\mathrm{AQL}_{\mathrm{p}}\right)\right]$ has been placed at $10 \%$ while consumer risk $\mathrm{P}\left(\mathrm{LTPD}_{\mathrm{c}}\right)$ remains at $5 \%$. AQL continues to be 0.005 . The resulting unique sampling plan is $P L(3000,1400,9)$. The buyer should be very pleased with this plan represented by a risk factor of $4.7 \%$, while on the other side, the supplier finds his position weakened, as he is obligated to produce at a relatively high-quality rate $\mathrm{AQL}$ of 0.005 and must confront a risk factor of $9.7 \%$. Once again, the difference is large between the outcomes of the hypergeometric and the binomial probability functions.

The last case in Table 4, where both consumer and producer risks are $10 \%$, is not analyzed due to its very rare occurrence.

What is unclear in traditional acceptance sampling is the necessity of linking AQL exclusively to the producer and LTPD exclusively to the consumer. In reality, the consumer should also be preoccupied with a value of AQL, as should the producer with LTPD. We also question why type I error is always associated with the producer as producer risk, and likewise, the same question arises with consumer risk which is necessarily associated with type II error. The resolution of these questions is new to the literature and the remainder of this article will elaborate a response. In the next sections, we show that hypothesis test concepts from NP are relevant to practical applications of acceptance sampling, but only if the specific nature of the decision maker is taken into account.

\section{Acceptance sampling via hypothesis tests}

Historically, the work of Dodge and Romig (1929) appeared before the concepts of hypothesis testing received wide acceptance in practice. Their work depends exclusively on probability functions, and the probabilistic interpretation of the concepts of producer and consumer risk some years before Neyman and Pearson (1933) offered their seminal interpretation of type I and type II error.

DR worked in industry and commerce and, subsequently, the design of acceptance sampling they developed, because of the innate conflict between buyers and sellers, was strictly applicable to this environment. Our review of hypothesis testing is at most a simple skeleton of the relevant area of scientific methodology, better elaborated in works like Rice (1995, chapter 9) and the original work of Neyman and Pearson (1933). Nevertheless, our interpretation of acceptance sampling in light of hypothesis testing is new to the literature. First, we will concentrate on the nature and definition of the null hypothesis.

Simply stated, a hypothesis is a clear statement of a characteristic of a population and usually its numerical 
Fig. 3 ROC curve

hypergeometric and binomial sampling plan $P L(3000,1600$, c) for Case 5-5 from Table 4 . $\mathrm{AQL}=0.5 \%$ and $\mathrm{LTPD}=1.0 \%$

Fig. 4 ROC curve hypergeometric and binomial sampling plans PL(3000, 1400, c): case 5-10 from Table 4 $\mathrm{AQL}=0.5 \%$ and $\mathrm{LTPD}=1.0 \%$

Fig. 5 ROC curve hypergeometric and binomial sampling plans $P L(3000,1400$, $c)$ : advantageous to the consumer Case 10-5 $\mathrm{AQL}=0.5 \%$ and $\mathrm{LTPD}=1.0 \%$
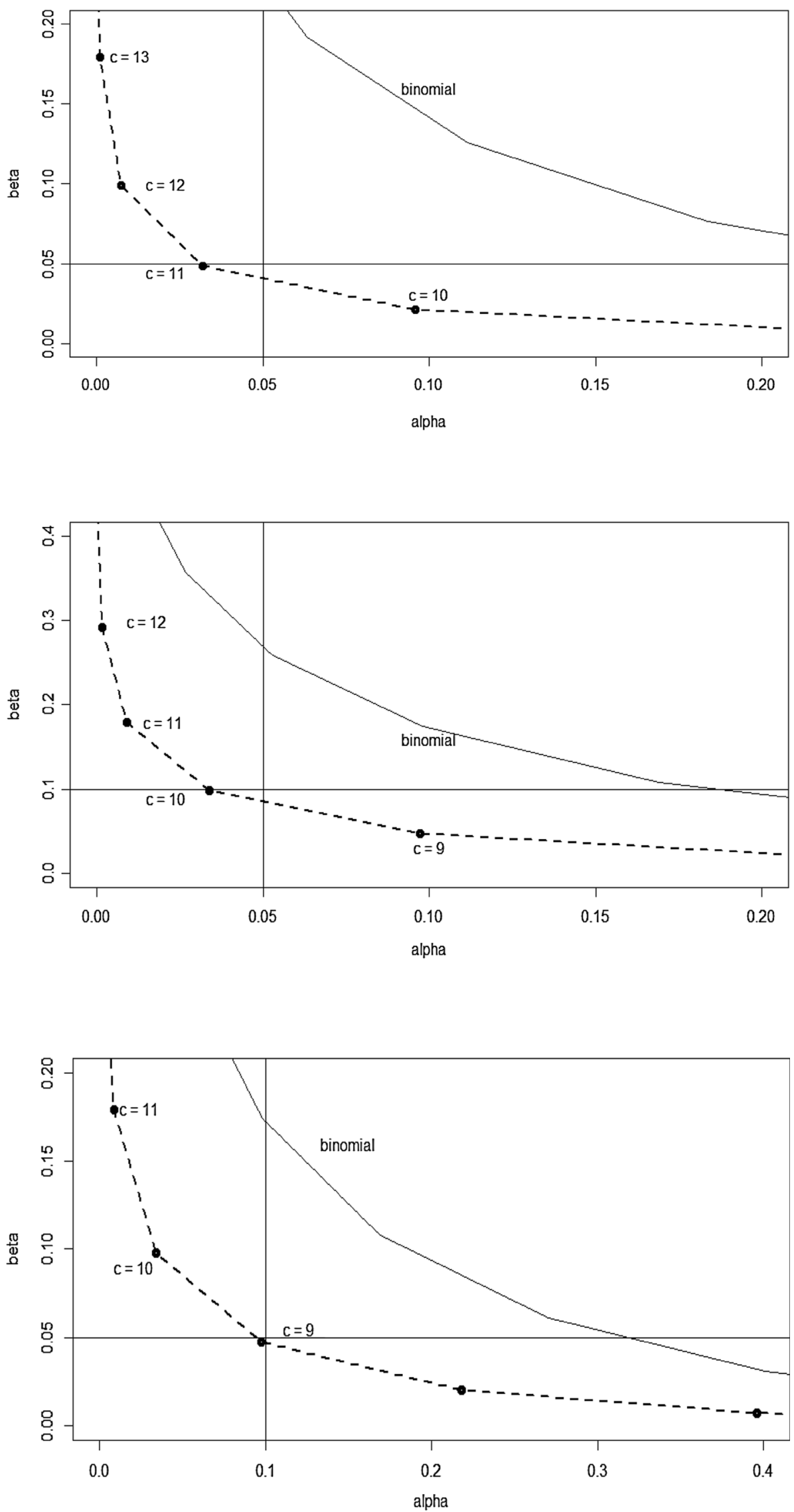
value, or of a relationship among characteristics (something happens associated with something else), that may or may not be true. It carries with itself a doubt that calls for evaluation. Hypotheses are not unique but come in pairs (or multiples not reviewed here) of exclusive statements in the sense that if one statement is true then the other statement is false. When the decision maker judges one of the hypotheses as true, he necessarily judges the other as false. The lot is conforming or non-conforming. Vaccination drives reached the target population or not. Your candidate is winning the election campaign or is not winning. The accused is either innocent or guilty.

From the viewpoint of the decision maker, the consequences of incorrectly rejecting one of the hypotheses are usually more severe than those of incorrectly rejecting the other. As we have seen above, lots are either conforming or non-conforming, and for the consumer for instance, incorrectly accepting the non-conforming lot committing the false negative can be disastrous. In such a case, the null hypothesis is the statement that costs the most when wrongly judged (Rice 1995). This nomenclature serves to organize relevant social or industrial questions or laboratory experiments. The null carries the symbol Ho, the alternative hypothesis Ha. From the consumer's point of view, therefore, the null hypothesis is that the lot is nonconforming. Rejecting this null when it is true incurs extremely high costs for the consumer. In similar fashion but from the producer point of view, the null hypothesis is that the lot is conforming, because as mentioned already, rejecting this null has extremely high costs for the producer. We illustrate these differences in Table 5.

The hypothesis test attempts to classify the lot by accepting or rejecting the null usually by examining a small random sample. In Table 5, the decision maker indicates states of the null by examining a small sample of the population and consequently accepting or rejecting the null hypothesis. For the purpose of this article, we follow statistical methodology; a random sample from the relevant population indicates the state of the null. However, other methods are available outside the realm of Statistics, like flipping a coin or throwing seashells in a basket. In the population itself, the null is, in reality, either true or false, even though this condition in the population is unknown to the decision maker, and continues to be unknown even

Table 5 Hypotheses and the decision maker

\begin{tabular}{lll}
\hline & Consumer & Producer \\
\hline Ho: null hypothesis & $\begin{array}{c}\text { Low-quality } \\
\text { unacceptable lot }\end{array}$ & $\begin{array}{c}\text { High-quality } \\
\text { acceptable lot }\end{array}$ \\
$\begin{array}{l}\text { Ha: alternative } \\
\text { hypothesis }\end{array}$ & $\begin{array}{c}\text { High-quality } \\
\text { acceptable lot }\end{array}$ & $\begin{array}{c}\text { Low-quality } \\
\text { unacceptable lot }\end{array}$ \\
\hline
\end{tabular}

after the sampling procedure. As shown in Table 6, the result of the acceptance sampling procedure can have one of four possible results.

Two quadrants are labeled as correct, and the other two as errors. In general, we would like to maximize the probability of falling into the correct boxes and minimize the probability of error. Following NP, accepting as true the false null is a type II error, whereas rejecting a true null is type I error. The exact definition of the null hypothesis is crucial, and as stated above should be defined as the condition that incurs the highest cost if chosen in error. The choice of which of the two hypotheses is to be the null depends, therefore, on the decision maker, and how he perceives the distinctive costs of the two errors.

In acceptance sampling, the statistical test of the validity of the null hypothesis is based on the relationship between $x$ and $c$, given the value of $n$. When the null hypothesis suffers rejection, the researcher makes an inference as inference as to the population value of the characteristic in the hypothesis test. However, the value of the characteristic is not a point estimate but rather only a probabilistic generalization of a region of values inferred from $x$ and $c$. In other words, the rejection of the null does not imply anything about the point value of $p$ itself other than its role in determining the conformance of the lot. Even the construction of confidence intervals do not supply isolated point estimates of the population parameters but rather an interval of probable variation around the point estimate.

We have assumed in the discussion above that the null for the producer is that the lot is conforming, or analogously the production line is stable producing a good product. The engineer who tries to correct problems that do not exist (he rejects the null when it is true) is wasting precious time in worthless activities. This is a type I error, the basis of the $p$ value ${ }^{7}$ to the statistician and equivalent to producer risk for the industrial engineer. Increasing the value of the cutoff $c$ will decrease the probability of type I error by making rejection of the lot more difficult. However, increasing the value of $c$ makes acceptance easier and therefore will increase the probability of type II error, $\beta_{p}$. Considering that type II error is relatively less important for the producer, the tradeoff tends to be attractive for the producer. From the consumer's side of the story and contrary to the producer, the null should be that the lot is nonconforming, in other words, that the consumer should naturally distrust the quality of the lot or process.

In traditional acceptance sampling, consumer risk has been exclusively the subject of the consumer, and producer risk the subject of the producer. Nonetheless, there is no

\footnotetext{
${ }^{7}$ Recently much controversy has surrounded the concept of the $p$ value, specifically its incorrect use in published works. See Gelman (2013) for clarification of the problem.
} 
Table 6 Occurrences for hypothesis tests of the consumer, and Table 8 that of the producer

\begin{tabular}{lll}
\hline $\begin{array}{l}\text { Real states of the null } \\
\text { hypothesis Ho in } \\
\text { the population }\end{array}$ & $\begin{array}{l}\text { Decision maker chooses between } \\
\text { states of the null hypothesis Ho }\end{array}$ \\
\cline { 2 - 3 } & Accept Ho & Reject Ho \\
\hline $\begin{array}{l}\text { True Ho } \\
\text { False Ho }\end{array}$ & $\begin{array}{ll}\text { Correct } & \text { Type I error } \\
\text { Correct }\end{array}$ \\
\hline
\end{tabular}

conceptual reason to restrict each risk factor to only one adversary in the negotiation process. Logically, there is no reason why the producer should not recognize and react to the probability of accepting the bad lot what has been called up to now consumer risk. Accepting the bad lot is certainly a problem for the producer, however, as described earlier a problem of secondary intensity. Likewise, rejecting the good lot and committing a false positive is also a problem for the consumer but of only moderate intensity. From the viewpoint of the consumer we have, $\mathrm{LTPD}_{\mathrm{c}}$ and $P\left(\mathrm{LTPD}_{\mathrm{c}}\right)$ and furthermore $\mathrm{AQL}_{\mathrm{c}}$ and $P\left(\mathrm{AQL}_{\mathrm{c}}\right){ }^{8}{ }^{8}$ Here the consumer feels both risks, primarily the probability of accepting bad lots $P\left(\mathrm{LTPD}_{\mathrm{c}}\right)$, and less intensely the probability of rejecting good lots $\left[1-P\left(\mathrm{AQL}_{\mathrm{c}}\right)\right]$. The consumer can and should construct his sampling plan using both risks recognizing that less consumer risk should be his objective since its repercussions are more costly, while he tolerates more secondary risk. Specifically, the consumer, for example, could use a $P\left(\mathrm{LTPD}_{\mathrm{c}}\right)$ of $3 \%$ and a $\left[1-P\left(\mathrm{AQL}_{\mathrm{c}}\right)\right]$ of $10 \%$.

The producer could follow analogous procedures. The producer will apply not only the risk pair $\mathrm{AQL}_{\mathrm{p}}$ and $\left[1-P\left(\mathrm{AQL}_{\mathrm{p}}\right)\right]$ as would be traditional, but also the risk pair $\mathrm{LTPD}_{\mathrm{p}}$ and $P\left(\mathrm{LTPD}_{\mathrm{p}}\right)$ recognizing that the producer suffers from his own secondary risk even though by a lesser degree. For example, the producer could set $\left[1-P\left(\mathrm{AQL}_{\mathrm{p}}\right)\right]$ to $1 \%$ and $P\left(\mathrm{LTPD}_{\mathrm{p}}\right) 10 \%$.

The correct routine for hypothesis testing is that first, we elaborate the hypothesis by conceptualizing an important characteristic of the population, and only then, in a second step, are the relevant probabilities of the resulting sampled data calculated. More importantly, the state of the hypothesis in the population is usually unknown, and will remain that way forever. Of course, one day in the future, end users will know the quality of the lot with certainty, depending upon the availability of all appropriate data. Nevertheless, even after ample time has passed, lot quality will remain elusive.

This section has been a first attempt at generalizing risk factors to both players. We have allowed consumers to recognize producer risk and producers may now

\footnotetext{
${ }^{8}$ Subscripts $\mathrm{P}$ for producer and $\mathrm{C}$ for consumer.
}

acknowledge consumer risk. However, we have kept the two decision makers each as a self-determining unit. In later sections, we attempt to generalize acceptance sampling to the case of both risks applying to both producer and consumer simultaneously.

\section{Acceptance sampling from the viewpoint of the decision maker}

As seen above, the definition of the null depends on point of view. The producer must decide on a limiting value for $\mathrm{AQL}_{\mathrm{p}}$ above which the lot is unacceptable. In other words, if the fraction defective $p$ is less than $\mathrm{AQL}_{\mathrm{p}}\left(p \leq \mathrm{AQL}_{\mathrm{p}}\right)$, then the lot is defined by the producer as conforming. On the other hand, for the consumer, $\left(p \leq \mathrm{LTPD}_{\mathrm{c}}\right)$ defines the conforming lot. Under no circumstances should we assume that the values of $\mathrm{AQL}_{\mathrm{p}}$ and $\mathrm{LTPD}_{\mathrm{c}}$ are equal, nor should they be, given that they come from distinct decision makers on opposite sides of the negotiation.

Each decision maker should weigh the importance of two risks when constructing his own sampling plan: a primary risk based on his own null hypothesis and a secondary risk based on his own alternative hypothesis. For the consumer, the relation $p \leq \mathrm{AQL}_{\mathrm{C}}$ defines secondary risk. Likewise, $p>\mathrm{LTPD}_{\mathrm{p}}$ defines the secondary risk for the producer. Consequently, Eq. (1) and (2) can be rewritten as the following, featuring either the viewpoint of the producer emphasizing $\mathrm{AQL}_{\mathrm{p}}$ and $\mathrm{LTPD}_{\mathrm{p}}$, or the consumer emphasizing $\mathrm{LTPD}_{\mathrm{c}}$ and $\mathrm{AQL}_{\mathrm{c}}$, respectively. ${ }^{9}$

$P\left(x>c / p \leq \mathrm{AQL}_{\mathrm{P}}\right)=P(\mathrm{FP})=\alpha_{\mathrm{P}}$

$P\left(x \leq c / p>\mathrm{LTPD}_{\mathrm{P}}\right)=P(\mathrm{FN})=\beta_{\mathrm{P}}$

$P\left(x \leq c / p>\mathrm{LTPD}_{\mathrm{C}}\right)=P(\mathrm{FN})=\alpha_{\mathrm{C}}$

$P\left(x>c / p \leq \mathrm{AQL}_{\mathrm{C}}\right)=P(\mathrm{FP})=\beta_{\mathrm{C}}$

The probability of type I errors $\left(\alpha_{\mathrm{P}}\right.$ and $\left.\alpha_{\mathrm{C}}\right)$ called primary risks is given in Eqs. (1a) and (1b). Both equations represent the rejection of the respective null when it is true. Similarly, the probability of type II errors $\left(\beta_{\mathrm{P}}\right.$ and $\left.\beta_{\mathrm{C}}\right)$ here called secondary risks is given in Eqs. (2a) and (2b). These four equations can be collapsed back to the original Eqs. (1) and (2) by assuming unique values of $c$ and $n$ and assuming $\mathrm{AQL}_{\mathrm{p}}=\mathrm{AQL}_{\mathrm{c}}$ and $\mathrm{LTPD}_{\mathrm{c}}=\mathrm{LTPD}_{\mathrm{p}}$. Consequently, $\alpha_{\mathrm{P}}=\beta_{\mathrm{C}}$ and $\alpha_{\mathrm{C}}=\beta_{\mathrm{P}}$. Considering that the producer and the consumer are independent decision makers, there is no reason to expect these equalities in the real world. It is essential for the logic of this paper to understand the relative importance of FP and FN for the decision makers. For producers, FPs are more important, and for

\footnotetext{
9 We have not used subscripts for all the parameters, hopefully without loss of clarity.
} 
Table 7 Alternative occurrences for consumer

\begin{tabular}{lll}
\hline $\begin{array}{l}\text { Reality of null Ho in the population: } \\
\text { lot is non-conforming }\end{array}$ & \multicolumn{2}{l}{ Consumer chooses between states of the null hypothesis Ho: lot is non-conforming } \\
\cline { 2 - 3 } & Accept Ho $x>c$ & Reject Ho $x \leq c$ \\
\hline True Ho & $P(\mathrm{TP})$ & $\alpha_{C}=\mathrm{P}(\mathrm{FN})$ type $\mathrm{I}$ error \\
$p>\mathrm{LTPD}_{\mathrm{c}}$ & $P\left(x>c / p>\mathrm{LTPD}_{\mathrm{c}}\right)$ & $P\left(x \leq c / p>\mathrm{LTPD}_{\mathrm{c}}\right)$ \\
True Ha & $\beta_{C}=\mathrm{P}(\mathrm{FP})$ type II error & $P(\mathrm{TN})=1-\beta_{C}$ \\
$p \leq \mathrm{AQL}_{\mathrm{c}}$ & $P\left(x>c / p \leq \mathrm{AQL}_{\mathrm{c}}\right)$ & $P\left(x \leq c / p \leq \mathrm{AQL}_{\mathrm{c}}\right)$ \\
\hline
\end{tabular}

$F N$ false negative, $F P$ false positive, $T P$ true positive, $T N$ true negative

consumers, FNs are more important as illustrated in the next tables. One further equation completes the concepts for hypothesis testing: $\alpha<\beta$, reflecting the higher costs of type I error. Table 7 elaborates the point of view of the consumer, and Table 8 that of the producer. At the buyer's warehouse, the inspection will indicate the high or low quality of the lot. In some very rare cases, the buyer accepts the lot without inspection implying total confidence between buyer and seller, but considering the rarity of mutual confidence in the marketplace, the buyer usually undertakes some kind of inspection. The desire of the buyer at the moment of inspection is to maximize the probability of accepting good lots, a true negative $(T N)$, or rejecting bad ones, a true positive (TP). There is a tradeoff between the probability of erroneously accepting the bad lot, a false negative (FN), and the probability of erroneously rejecting the good lot, a false positive $(F P)$. An appropriate probability function can measure these probabilities and form the basis for the construction of sampling plans.

For the consumer, FN is an error of disastrous proportions, and as stated above, DR calls the probability of this occurrence consumer risk. Accepting the defective lot means placing inadequate material on the assembly line or on the store shelves. On the other hand, the consumer who rejects good lots commits $F P$, a lesser error, even though the result may be costly in terms of unnecessary replacement costs and delays. DR and all posterior literature in acceptance sampling assume that the risk of rejecting acceptable lots has no relevance to the consumer. Even though this assumption may have been necessary to simplify the probability calculations in the early 1900s, today's calculators have made this assumption reasonably gratuitous. Logically, the sampling plan that satisfies the consumer will have as a sample cutoff a very small number of defective items $c$ and a relatively large sample size $n$, facilitating rejection. This means that some good lots will be judged guilty as non-conforming and rejected, but this consequence is less troublesome to the consumer. For instance, when a multinational makes purchases from a small supplier, the multinational sets $c$ at zero, compelling the small supplier to rectify some lots unjustly rejected (Squeglia 1994). Logically, since its repercussions are more severe, the decision maker should hold primary risk to lower levels when compared to secondary risk.

Table 8 describes the point of view of the producer. The null for the producer is that the lot is conforming. In this case, type I error means that the lot is actually conforming but has been rejected by the producer. As always and by definition, type I error is more costly than type II error.

Immediately after the fabrication of the lot, but before expediting the lot to the consumer, an inspection should occur to verify its quality level $p$. The interest of the producer is to expedite lots with acceptable quality to assure customer satisfaction and future transactions. When an inspection by the producer results in rejected lots, the common practice is to apply universal $100 \%$ inspection to the rejected lot still in the factory replacing all bad parts. From the producer point of view, the major worry is the probability of the rejection of good lots $\mathrm{P}(x>c)$ $\left.p \leq \mathrm{AQL}_{\mathrm{p}}\right)$, which are false positives FP known as producer risk, a false alarm calling the producer to action where action is not necessary. The producer priority is to avoid the rejection of good lots, and, consequently, the sampling plan includes relatively large $c$. Clearly, with $c$ large, the producer judges some bad lots as conforming, but as emphasized above this error is less troublesome for the producer.

\section{Calculating the unique plan that satisfies both parties, all risks}

This section illustrates what happens when taking into account both consumer and producer simultaneously, and assumes that each adversary worries about both kinds of risk, the probability of accepting the bad lot and the probability of rejecting the good lot. Moreover, each adversary will prioritize one of the two risks and downgrade the importance of the other. In other words, we should select only those sampling plans where $\alpha<\beta$. This generalization of acceptance sampling is not present in the literature. 
Table 8 Alternative occurrences for producer

Reality of null Ho: lot is conforming Producer chooses between states of the null hypothesis Ho: lot is conforming

\begin{tabular}{llc} 
& Accept Ho $x \leq c$ & Reject Ho $x>c$ \\
\hline True Ho $p \leq \mathrm{AQL}_{\mathrm{p}}$ & $P(\mathrm{TN}) \mathrm{P}\left(x \leq c / p \leq \mathrm{AQL}_{\mathrm{p}}\right)$ & $P(\mathrm{FP})$ type I error: $\alpha_{\mathrm{p}}=\mathrm{P}(x>c l$ \\
& $p \leq \mathrm{AQL})$ & $P(\mathrm{TP}) \mathrm{P}\left(x>c / p>\mathrm{LTPD}_{\mathrm{p}}\right)$ \\
True Ha $p>\mathrm{LTPD}_{\mathrm{p}}$ & $P(\mathrm{FN})$ type II error: $\beta_{\mathrm{p}}=P(x \leq c l$ & $\sum P=1$ \\
& $\left.p>\mathrm{LTPD}_{\mathrm{p}}\right)$ & \\
\hline
\end{tabular}

$F N$ false negative, $F P$ false positive, $T P$ true positive, $T N$ true negative

As stated earlier the possibility of letting bad product pass through undetected is only a minor nuisance for the producer and so he tolerates this error at higher levels of risk. In Table 9, we allow the values of $\alpha$ and $\beta$ to vary and revised plans are reported. Sample size shows itself to be very sensitive to $\beta$ risk. When allowing for higher values of secondary $\beta$ risk, these new configurations can greatly reduce the cost of sampling. A small secondary risk of 5\% requires a sample size of 1600 , whereas allowing for more secondary risk brings sample size down to 1000 . The hypergeometric distribution is the basis of all of the calculations in Table 9, with two exceptions commented on later. Producer and consumer fix primary risks at less than 5\% and secondary risks vary. Lot size is 3000 units. LTPD is $1 \%$ and AQL is $0.5 \%{ }^{10}$ The sampling plan $P L(N, n, c)$ should satisfy these five parameters. The resulting sample sizes are much smaller than lot size 3000. We have devoted two lines in Table 9 to the binomial distribution to illustrate its inaccuracy. In the first line, the sample size is equal to the size of the lot, an illogical result since sampling by definition requires samples smaller than the population. 100\% inspection is not sampling and therefore there is no need to specify a value for $c$. This illogical result is due to the large variance formed by the binomial distribution explained in Appendix "Hypergeometric distribution". Generally, the binomial yields pessimistic results; measures of risk and dispersion are overestimated. Surely, such pessimism could lead to discouragement for sampling procedures and even the abandonment of sampling programs.

Figure 6 shows the appropriate ROC curves for the consumer sampling plan $P L(3000,1400$, c) and $P L(3000$, 1400, c) for the producer. The dialog between the two parties, in this case, is not so difficult since the two plans are very similar. The two parties could use the same sample of 1400 and proceed with the counting of defective items. The sampling procedure would be inconclusive in only one case when $x=10$. The cutoff value for the producer is the value of $10(x \leq 10)$ meaning that the producer will see the lot as good quality, whereas the consumer will see this

\footnotetext{
${ }^{10}$ Factories and consumers will have independent values for LTPD and AQL. The values in this example are arbitrary but originate from the experience of the author.
}

value of $x$ as demonstrating the low quality of the lot $(x>9)$. The appearance of exactly 10 defective items in the sample will occur in only 5\% of the lots and therefore should not cause extreme conflict between parties.

The examples above have all used $N=3000$ for illustrative purposes for didactic reasons only. In Table 10, we have collected results that permit population size to vary. Noteworthy in the table is the similarity for plans among the last three population sizes of 20,000, 30,000, and 40,000. Sample size and cutoff values are all the same $\operatorname{PL}(n, 3000, c=20,21)$ but risk factors are not, as population size increases risk factors also increase, once again showing the necessity of using the hypergeometric distribution for obtaining more accurate results even with relatively large populations.

\section{Conclusions}

The paper has shown that sampling plans should be true to the data and the situation they represent. When lot sizes are finite, statistical approximations may lead to serious estimation errors. Since the process of sampling is inherently error prone, the sampling process should employ only the most accurate data available, including lot size. The priority for researchers in any area should be the utilization of the most appropriate formulations, like the hypergeometric distribution in sampling plans, so that unnecessary additions to inherent errors do not occur.

There are several directions for advancing this research, for example, the important area of Bayesian statistics not mentioned in the paper. This was not because we wanted to devalue its appropriateness for sampling plans, but rather because its contribution would be doubtful to the questions of this paper, based entirely on traditional frequentist statistics. Bayesian approaches will be an important part of future research. The work of Suresh and Sangeetha (2011) is especially interesting in this regard. Finally, we suggest that the application of the R package Shiny (shiny.rstudio.com, RSTUDIO 2013) could facilitate the day-to-day operation of the approach proposed here. Contributions to the literature have already gone in this direction (Hund 2014). 
Table 9 Hypergeometric sampling plans $P L(3000, n, c)$ for several values of $\alpha$ and $\beta, N=3000, \mathrm{LTPD}_{\mathrm{p}}$ is $1 \%$; $\mathrm{AQL}_{\mathrm{p}}$ is $0.5 \%$

\begin{tabular}{|c|c|c|c|c|c|c|}
\hline \multirow{2}{*}{$\begin{array}{l}\text { Consumer } \\
\alpha_{C}=P\left(\mathrm{LTPD}_{\mathrm{c}}\right)\end{array}$} & \multirow{2}{*}{$\begin{array}{l}\text { Secondary } \\
\beta c=1-P\left(\mathrm{AQL}_{\mathrm{c}}\right)\end{array}$} & \multirow{2}{*}{$\begin{array}{l}\text { Producer } \\
\alpha_{p}=1-P\left(\mathrm{AQL}_{\mathrm{p}}\right)\end{array}$} & \multirow{2}{*}{$\begin{array}{l}\text { Secondary } \\
\beta_{p}=P\left(\mathrm{LTPD}_{\mathrm{p}}\right)\end{array}$} & \multicolumn{3}{|c|}{ Sampling plan } \\
\hline & & & & $n$ & $c$ & $c / n$ \\
\hline Binomial approximation & .032 & .08 & 3000 & 22 & .007 & \\
\hline$\ldots$ & $\ldots$ & .032 & .049 & 1600 & 11 & .007 \\
\hline .049 & .059 & $\ldots$ & $\ldots$ & 1500 & 10 & .007 \\
\hline$\ldots$ & $\ldots$ & .017 & .099 & 1500 & 11 & .007 \\
\hline .047 & .097 & $\ldots$ & $\ldots$ & 1400 & 9 & .006 \\
\hline$\ldots$ & $\ldots$ & .034 & .098 & 1400 & 10 & .007 \\
\hline .043 & .213 & $\ldots$ & $\ldots$ & 1200 & 7 & .007 \\
\hline$\ldots$ & $\ldots$ & .033 & .175 & 1200 & 9 & .008 \\
\hline .039 & .29 & $\ldots$ & $\ldots$ & 1100 & 6 & .005 \\
\hline$\ldots$ & $\ldots$ & .018 & .288 & 1100 & 9 & .008 \\
\hline .035 & .381 & $\ldots$ & $\ldots$ & 1000 & 5 & .005 \\
\hline$\ldots$ & $\ldots$ & .03 & .285 & 1000 & 8 & .008 \\
\hline Binomial approximation & .031 & .457 & 1000 & 9 & .009 & \\
\hline
\end{tabular}

Fig. 6 ROC curve sampling plans for producer PL $(3000$, $1400,10)$ and consumer $\operatorname{PL}(3000,1400,9)$

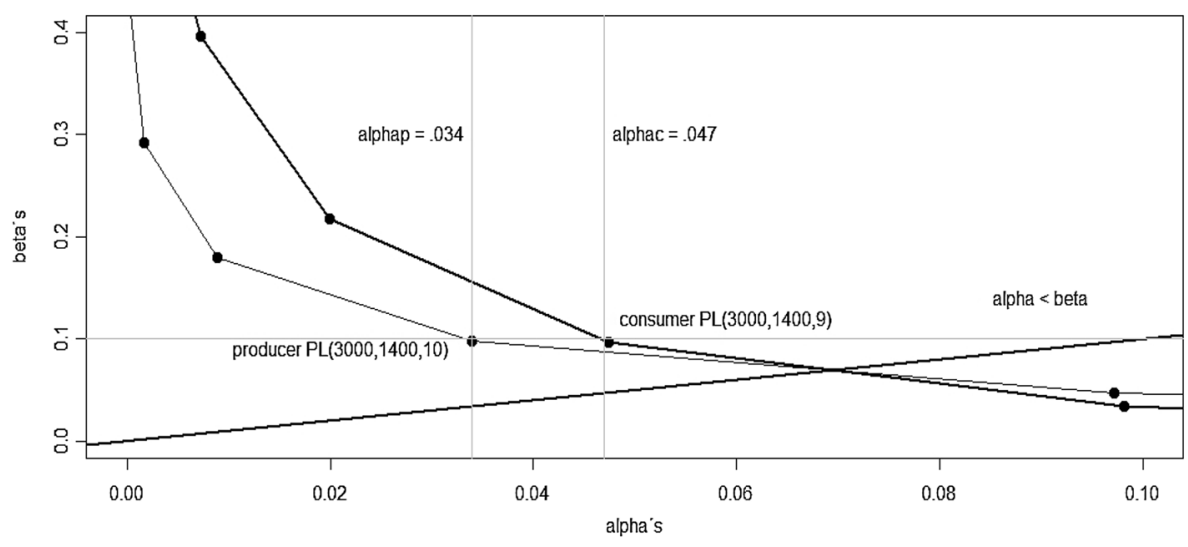

Table 10 Hypergeometric sampling plans $P L(N, n, c)$ for several lot sizes given $\mathrm{LTPD}_{\mathrm{p}}$ is $1 \%$; $\mathrm{AQL}_{\mathrm{p}}$ is $0.5 \%$

\begin{tabular}{lllllll}
\hline Consumer & Secondary & Producer & \multicolumn{2}{l}{ Secondary } & \multicolumn{3}{l}{ Sampling plan } \\
\cline { 5 - 7 }$\alpha_{C}=P\left(\mathrm{LTPD}_{\mathrm{c}}\right)$ & $\beta c=1-P\left(\mathrm{AQL}_{\mathrm{c}}\right)$ & $\alpha_{p}=1-P\left(\mathrm{AQL}_{\mathrm{p}}\right)$ & $\beta_{p}=P\left(\mathrm{LTPD}_{\mathrm{p}}\right)$ & $N$ & $n$ & $c$ \\
\hline .049 & .059 & $\ldots$ & $\ldots$ & 3000 & 1500 & 10 \\
$\ldots$ & $\ldots$ & .017 & .099 & 3000 & 1500 & 11 \\
.015 & .054 & $\ldots$ & $\ldots$ & 5000 & 2300 & 15 \\
$\ldots$ & $\ldots$ & .022 & .031 & 5000 & 2300 & 16 \\
.035 & .071 & $\ldots$ & $\ldots$ & 10,000 & 2400 & 16 \\
$\ldots$ & $\ldots$ & .038 & .059 & 10,000 & 2400 & 17 \\
.025 & .066 & $\ldots$ & $\ldots$ & 20,000 & 3000 & 20 \\
$\ldots$ & $\ldots$ & .039 & .041 & 20,000 & 3000 & 21 \\
.028 & .072 & $\ldots$ & $\ldots$ & 30,000 & 3000 & 20 \\
$\ldots$ & $\ldots$ & .044 & .045 & 30,000 & 3000 & 21 \\
.03 & .074 & $\ldots$ &. & 40,000 & 3000 & 20 \\
$\ldots$ & $\ldots$ & .046 & .047 & 40,000 & 3000 & 21 \\
\hline
\end{tabular}

following a careful reassessment of NP. The public health literature for LQAS is ambiguous on the issue of defining the null hypothesis, depending on the author and the area under scrutiny (Biedron, et al. 2010; Rhoda et al. 2010; Pagano and Valadez 2010). We suggest that the sampling
We intend to expand this research into the areas of public health and political polling. Public health has seen extensive applications of traditional acceptance sampling in lot quality assurance sampling (LQAS), but in our view, this area would benefit greatly from the reformulation 
plans should recognize and emphasize the viewpoint of the target population as Rhoda et al. (2010) argues. For example in the case of a vaccination campaign where coverage is of major interest, the population (analogous to the consumer) should suggest a null that would define the cutoff where coverage is inadequate. A sample that indicates the target population is receiving adequate levels of coverage, when in fact coverage is inadequate, is a very serious error indeed.

For political polling, the decision makers perspective can come from the candidate (consumer of consulting services) or from the pollster (supplier, producer). The null for the candidate is that his adversary is winning the political campaign, analogous to the null of the buyer that lots are of bad quality. If in fact, the adversary is winning but the candidate believes that his own campaign is winning, the result for the candidate could be very costly. Falsely believing his campaign is ahead; he may diminish his efforts and consequently fall behind even more. This is type I error for the candidate. Public health and polling have already seen some progress in applying the new methods proposed here (Samohyl 2015, 2016).

Open Access This article is distributed under the terms of the Creative Commons Attribution 4.0 International License (http://crea tivecommons.org/licenses/by/4.0/), which permits unrestricted use, distribution, and reproduction in any medium, provided you give appropriate credit to the original author(s) and the source, provide a link to the Creative Commons license, and indicate if changes were made.

\section{Appendix}

\section{Hypergeometric distribution}

The most relevant characteristic of the hypergeometric distribution is that population size $N$ enters directly into its formulation contrary to other distributions like the binomial and Poisson. The hypergeometric mass function produces an estimate of the probability of $x$ defectives appearing in the sample, depending on lot quality $p=X / N$ and the sample size $n$. Note that the number of good parts in the lot is $(N-X)$, and the number of good parts in the sample is $(n-x)$. See Gonin (1936) for the development of the equation.

$$
\begin{aligned}
P h & =\frac{\frac{X !}{x !(X-x) !}+\frac{(N-X) !}{(n-x) !((N-X)-(n-x)) !}}{\frac{N !}{n !(N-n) !}}=\frac{\left(\begin{array}{c}
X \\
x
\end{array}\right)+\left(\begin{array}{c}
N-X \\
n-x
\end{array}\right)}{\left(\begin{array}{c}
N \\
n
\end{array}\right)} \\
& =\frac{\frac{(p N) !}{x !(p N-X) !}+\frac{((1-p) N) !}{(n-x) !(((1-p) N)-(n-X)) !}}{\frac{N !}{n !(N-n) !}}
\end{aligned}
$$

To simplify, we rewrite the hypergeometric mass function $h$ to emphasize dependence on the defective rate $p$.

$P_{h}(p)=h\{N, n, x, p\}$

Supplying numbers to $N, n, x$, we draw Fig. 7 to demonstrate this dependence graphically. As $p$ gets closer to zero, the probability of finding samples with $x=0$ becomes more likely, $P_{h}(p)$ approaches one. The step format for $N=500$ is due to the discrete nature of this noncontinuous distribution. Allowing $N$ to approach infinity in the hypergeometric distribution will result in the binomial distribution. Guttman et al. (1982, p. 30) demonstrates this theorem.

For acceptance sampling, the probability of accepting the lot is a cumulative sum containing $x=0,1,2, \ldots, c$, in the framework of the cumulative probability distribution. Specifically, in a sample of size $n$, from a population of size $N$, a lot is acceptable even though the sample may contain up to $c$ defective items. Consequently, with $H$ representing the cumulative hypergeometric distribution:

$P_{\mathrm{H}}(c)=H\{\operatorname{PL}(N, n, c), p\}$

The hypergeometric is more comprehensive and precise than the binomial and the Poisson. Even though the means are identical for all three distributions (np), the binomial variance $\operatorname{varb}(x)$ and the hypergeometric variance $\operatorname{varh}(x)$ have distinct values, but $\operatorname{varb}(x)$ is always greater than $\operatorname{varh}(x)$

$$
\begin{array}{r}
\operatorname{varb}(x)=n p(1-p), \\
\operatorname{varh}(x)=\operatorname{varb}(x) *(N-n) /(N-1)
\end{array}
$$

The Poisson variance $\operatorname{varp}(x)$ is simply $n p$, equal to its mean and, consequently, when $p$ is very small approaching zero, then $\operatorname{varb}(x) \approx \operatorname{varp}(x)$. The advantage of the hypergeometric is that its variance is smaller, and furthermore, much smaller when $N$ and $n$ are proximate values. The vertical axis in the next figure is the ratio $\operatorname{varh}(x) / \operatorname{varb}(x)$ which varies from 0.0 to 1.0 . The $x$ - and $y$ axes at the base are sample size $n$ and population size $N$. The figure shows that when $N$ is large and $n$ small, there is practically no difference between the two variances. However, when $N$ and $n$ have similar values, the result is a value of $\operatorname{varh}(x) / \operatorname{varb}(x)$ that approximates zero, the hypergeometric variance being much smaller than the binomial as seen in Fig. 8. Even when population size $N$ is 40,000 , and when sample size $n$ is relatively large, the difference between the two variances can be relevant. Considering the fact that the hypergeometric distribution is more general and more accurate than both the binomial and the Poisson, the question arises why do many applied areas of research continue to ignore the hypergeometric distribution? 
Fig. 7 Mass hypergeometric distribution $P_{h}(p)=h\{N, 300$, $0, p\}$

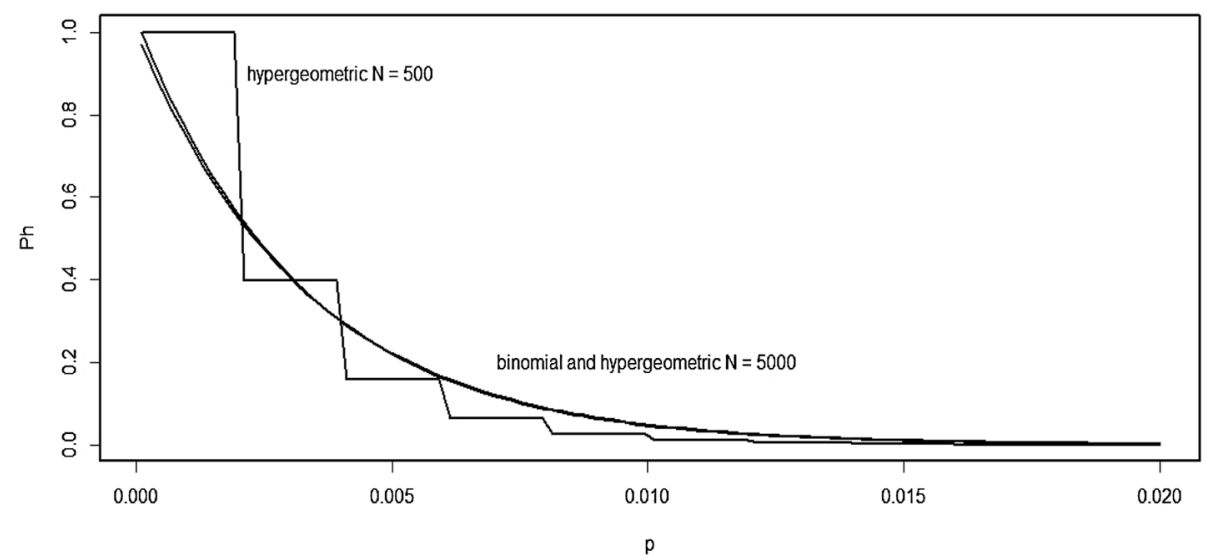

\section{Producer sampling plans recalculated} with the hypergeometric distribution

For the industrial practitioner who needs to use a sampling plan from the producer point of view right now urgently, go directly to Table 11 for producer sampling plans using the hypergeometric distribution. This table incorporates the most popular plans found in current standards for the producer, but risk factors come from the hypergeometric distribution. It is common in practice to use sampling plan tables without a careful understanding of the concepts that generate the numerical entries and may result in poor decision-making. Moreover, this may be the reason for disregarding the hypergeometric distribution as the proper base of the calculations.

Single sampling plans are ubiquitous in practically all industries and are the focus of this article. Double and multiple stage sampling plans may be less risky in a theoretical sense showing a lower probability of sampling error, however, applications on the shop floor require intensive training and the learning curve is uncomfortably steep. Single sampling plans, on the other hand, will reduce

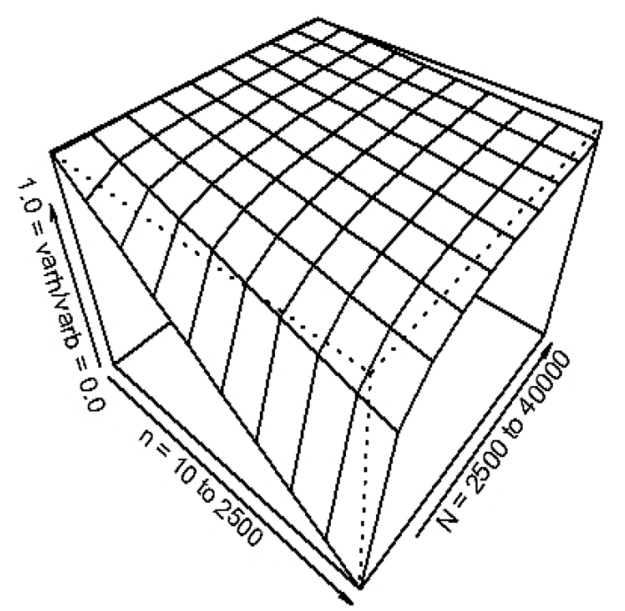

Fig. 8 Comparing hypergeometric and binomial variances costs significantly and even bring a new dynamic to the factory. The elimination of costly $100 \%$ total inspection will enhance the adoption of modern management techniques in general, and help to make negotiations between buyers and sellers more transparent and organized. Our intention is to show how to improve standard sampling plans like the ISO standards $(1999,1985)$ by recalculating tables with the hypergeometric distribution, and more importantly taking into account the correct usage of hypothesis testing. All major and most emerging economies have similar standards. Table 11 for producer sampling plans, the most utilized on a worldwide scale (but not always coherently), previews some important results from this paper. This table combines several tables of popular national and international sampling plans.

\section{How to use Table 11 step-by-step}

1. Choose the size of the lot $N$ from the second column.

2. The third column gives the sample size $n$.

3. Choose the worst level of quality permitted by the producer-acceptance quality level AQL. The table contains only four levels: $0.04,0.065,0.65,1 \%$, reflecting the very strict industry standards of modern manufacturing.

4. Column $c$ presents the cutoff number of failed parts in the sample that still allow for the acceptance of the lot as conforming. Consequently, if $c+1 \mathrm{bad}$ parts are found in the sample, this means the lot is rejected as non-conforming. To economize on resources and make the process even faster, sampling could be sequential and decisions taken even before all $\mathrm{n}$ items pass through inspection. $c+1 \mathrm{bad}$ parts may be found before the total sample $n$ is taken and rejection may already occur. Alternatively, $n-c$ parts could be sequentially sampled with no bad parts found, meaning that the lot should be accepted immediately. 
Table 11 Producer sampling plans

\begin{tabular}{|c|c|c|c|c|c|c|c|c|c|c|c|c|c|c|c|}
\hline \multirow{2}{*}{$\begin{array}{l}\text { ISO } \\
\text { Letter }\end{array}$} & \multirow{2}{*}{$\begin{array}{c}\text { ISO } \\
N\end{array}$} & \multicolumn{2}{|l|}{ ISO } & \multicolumn{3}{|c|}{ AQL $0.04 \%$} & \multicolumn{3}{|c|}{ AQL $0.065 \%$} & \multicolumn{3}{|c|}{ AQL $0.65 \%$} & \multicolumn{3}{|c|}{$A Q L 1 \%$} \\
\hline & & $n$ & $n / N$ & c & $\mathrm{P}(\mathrm{c})$ & $\begin{array}{l}\text { Producer } \\
\text { risk }\end{array}$ & $c$ & $P(c)$ & $\begin{array}{l}\text { Producer } \\
\text { risk }\end{array}$ & $c$ & $P(c)$ & $\begin{array}{l}\text { Producer } \\
\text { risk }\end{array}$ & c & $P(c)$ & $\begin{array}{c}\text { Producer } \\
\text { risk }\end{array}$ \\
\hline$A$ & 2 & 2 & 1.000 & 0 & 1.000 & 0.000 & 0 & 1.000 & 0.000 & 0 & 1.000 & 0.000 & 0 & 1.000 & 0.000 \\
\hline A & 8 & 2 & 0.250 & 0 & 1.000 & 0.000 & 0 & 1.000 & 0.000 & 0 & 1.000 & 0.000 & 0 & 1.000 & 0.000 \\
\hline B & 9 & 3 & 0.333 & 0 & 1.000 & 0.000 & 0 & 1.000 & 0.000 & 0 & 1.000 & 0.000 & 0 & 1.000 & 0.000 \\
\hline B & 15 & 3 & 0.200 & 0 & 1.000 & 0.000 & 0 & 1.000 & 0.000 & 0 & 1.000 & 0.000 & 0 & 1.000 & 0.000 \\
\hline C & 16 & 5 & 0.313 & 0 & 1.000 & 0.000 & 0 & 1.000 & 0.000 & 0 & 1.000 & 0.000 & 0 & 1.000 & 0.000 \\
\hline C & 25 & 5 & 0.200 & 0 & 1.000 & 0.000 & 0 & 1.000 & 0.000 & 0 & 1.000 & 0.000 & 0 & 1.000 & 0.000 \\
\hline D & 26 & 8 & 0.308 & 0 & 1.000 & 0.000 & 0 & 1.000 & 0.000 & 0 & 1.000 & 0.000 & 0 & 1.000 & 0.000 \\
\hline D & 50 & 8 & 0.160 & 0 & 1.000 & 0.000 & 0 & 1.000 & 0.000 & 0 & 1.000 & 0.000 & 0 & 1.000 & 0.000 \\
\hline $\mathrm{E}$ & 51 & 13 & 0.255 & 0 & 1.000 & 0.000 & 0 & 1.000 & 0.000 & 0 & 1.000 & 0.000 & 0 & 1.000 & 0.000 \\
\hline E & 90 & 13 & 0.144 & 0 & 1.000 & 0.000 & 0 & 1.000 & 0.000 & 0 & 1.000 & 0.000 & 0 & 1.000 & 0.000 \\
\hline $\mathrm{F}$ & 91 & 20 & 0.220 & 0 & 1.000 & 0.000 & 0 & 1.000 & 0.000 & 0 & 1.000 & 0.000 & 0 & 1.000 & 0.000 \\
\hline $\mathrm{F}$ & 150 & 20 & 0.133 & 0 & 1.000 & 0.000 & 0 & 1.000 & 0.000 & 0 & 1.000 & 0.000 & 0 & 0.867 & 0.133 \\
\hline G & 151 & 32 & 0.212 & 0 & 1.000 & 0.000 & 0 & 1.000 & 0.000 & 0 & 1.000 & 0.000 & 1 & 1.000 & 0.000 \\
\hline G & 280 & 32 & 0.114 & 0 & 1.000 & 0.000 & 0 & 1.000 & 0.000 & 0 & 0.886 & 0.114 & 1 & 0.987 & 0.013 \\
\hline $\mathrm{H}$ & 281 & 50 & 0.178 & 0 & 1.000 & 0.000 & 0 & 1.000 & 0.000 & 0 & 0.822 & 0.178 & 1 & 0.969 & 0.031 \\
\hline $\mathrm{H}$ & 500 & 50 & 0.100 & 0 & 1.000 & 0.000 & 0 & 1.000 & 0.000 & 0 & 0.729 & 0.271 & 1 & 0.919 & 0.081 \\
\hline J & 501 & 80 & 0.160 & 0 & 1.000 & 0.000 & 0 & 1.000 & 0.000 & 1 & 0.932 & 0.068 & 2 & 0.969 & 0.031 \\
\hline $\mathrm{J}$ & 1200 & 80 & 0.067 & 0 & 1.000 & 0.000 & 0 & 1.000 & 0.000 & 1 & 0.926 & 0.074 & 2 & 0.959 & 0.041 \\
\hline $\mathrm{K}$ & 1201 & 125 & 0.104 & 0 & 1.000 & 0.000 & 0 & 1.000 & 0.000 & 2 & 0.972 & 0.028 & 3 & 0.971 & 0.029 \\
\hline K & 3200 & 125 & 0.039 & 0 & 0.961 & 0.039 & 0 & 0.923 & 0.077 & 2 & 0.959 & 0.041 & 3 & 0.966 & 0.034 \\
\hline L & 3201 & 200 & 0.062 & 0 & 0.938 & 0.062 & 0 & 0.879 & 0.121 & 3 & 0.967 & 0.033 & 5 & 0.987 & 0.013 \\
\hline L & 10000 & 200 & 0.020 & 0 & 0.922 & 0.078 & 0 & 0.886 & 0.114 & 3 & 0.959 & 0.041 & 5 & 0.985 & 0.015 \\
\hline$M$ & 10001 & 315 & 0.031 & 0 & 0.880 & 0.120 & 0 & 0.825 & 0.175 & 5 & 0.984 & 0.016 & 7 & 0.987 & 0.013 \\
\hline M & 35000 & 315 & 0.009 & 0 & 0.881 & 0.119 & 0 & 0.820 & 0.180 & 5 & 0.983 & 0.017 & 7 & 0.985 & 0.015 \\
\hline $\mathrm{N}$ & 35001 & 500 & 0.014 & 0 & 0.818 & 0.182 & 1 & 0.961 & 0.039 & 7 & 0.983 & 0.017 & 10 & 0.987 & 0.013 \\
\hline $\mathrm{N}$ & 150000 & 500 & 0.003 & 0 & 0.818 & 0.182 & 1 & 0.958 & 0.042 & 7 & 0.982 & 0.018 & 10 & 0.987 & 0.013 \\
\hline $\mathrm{P}$ & 150001 & 800 & 0.005 & 1 & 0.959 & 0.041 & 1 & 0.905 & 0.095 & 10 & 0.983 & 0.017 & 14 & 0.984 & 0.016 \\
\hline P & 500001 & 800 & 0.002 & 1 & 0.959 & 0.041 & 1 & 0.904 & 0.096 & 10 & 0.983 & 0.017 & 14 & 0.983 & 0.017 \\
\hline Q & 1000000 & 1250 & 0.001 & 1 & 0.910 & 0.090 & 2 & 0.951 & 0.049 & 14 & 0.981 & 0.019 & 21 & 0.991 & 0.009 \\
\hline $\mathrm{R}$ & Level III & 2000 & & 2 & & & & & & 21 & & & & & \\
\hline
\end{tabular}

Source: ISO 2859-1 (1999) (Table 2, level II) risk revised using the hypergeometric distribution 
Fig. 9 OCC for $\mathrm{P}(\mathrm{p}) \mathrm{PL}(10,000, n, d)$

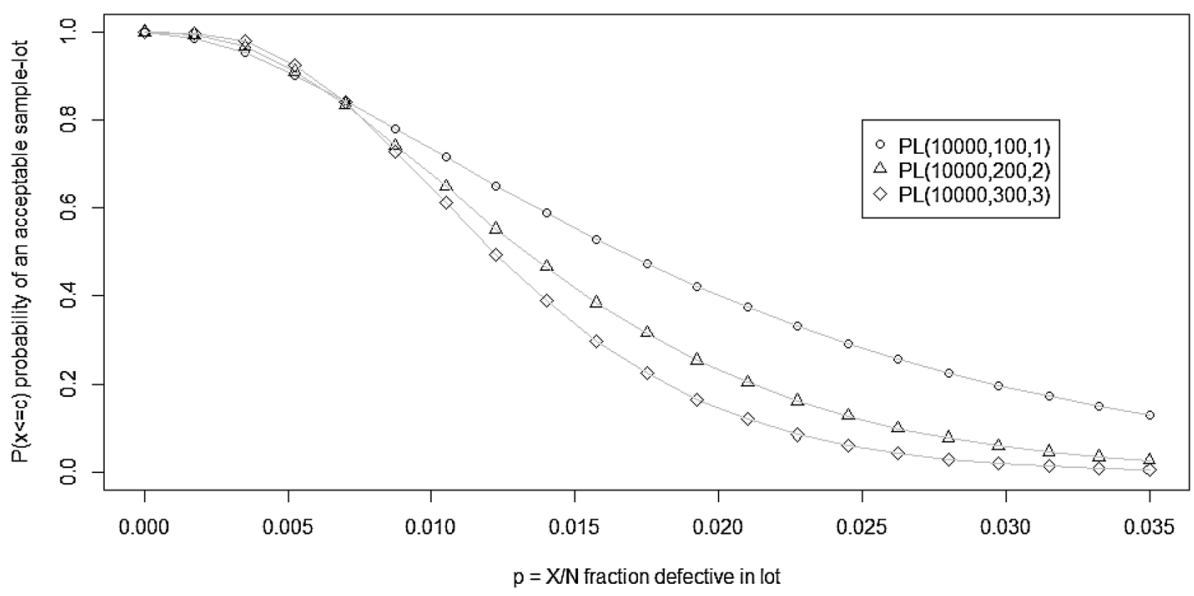

5. Finally, in the appropriate column check for producer risk.

\section{Comments on Table 11}

Following, are some comments about the revised numbers in the table.

- The column $n / N$ emphasizes the varying nature of the relative size of the sample compared to lot size. Large lots usually require proportionately smaller samples.

- Up to the letter F, $N=91$ and $n=20$, all plans use $c=0$ and therefore are extremely easy to apply on the shop floor. The advantage of these plans is that once a defective item appears sampling can stop given that the minimum condition for accepting the lot has been violated (Squeglia 1994).

- Popular thought has it that producer risk is constant throughout the standard tables, however when risk is recalculated using the hypergeometric distribution a notable dispersion of values is apparent. For example, for the $1 \%$ column (the last column of the table) producer risk varies from 0.0 to $13.3 \%$. Furthermore, note that there are many plans with zero risk for the producer.

\section{Operating characteristic curve (OCC)}

In this article, we suggest the use of the hypergeometric distribution as the basis for constructing sampling plans and not the approximations following the binomial and Poisson distributions. In all standard sampling plans including ISO $(1999,1985)$ and the Brazilian standards ABNT-NBR (1989a, b), graphical analysis of the relationship of $P()$ to several of its numerical characteristics is always included in the documentation, such as the form and functional relationship of $P()$ with lot quality $p$. The
Table $12 P L(10,000,100, \mathrm{c}) ; \mathrm{AQL}=0.005$ and $\mathrm{LTPD}=0.010$

\begin{tabular}{lll}
\hline $\mathrm{c}$ & $\alpha$ producer risk & $\beta$ consumer risk \\
\hline 9 & .305 & .003 \\
10 & .148 & .008 \\
11 & .055 & .021 \\
12 & .015 & .048 \\
13 & .002 & .098 \\
14 & .000 & .177 \\
15 & .000 & .288 \\
\hline
\end{tabular}

graphical representation of $P()$ and $p$ is known as the operating characteristic curve (OCC). ${ }^{11}$ Along the curve, the parameters of the sampling plan $\operatorname{PL}(N, n, c)$ are constant (Eq. 6). As the quality of the lot deteriorates with $p$ increasing, the probability of getting a high-quality sample $P(x \leq c)$ diminishes, or inversely, the probability of getting a low-quality sample $1-P(x \leq c)$ increases. In Fig. 9, we illustrate three different plans for lot size $N=10,000$. All plans are almost identical for high-quality lots up to $p=0.007$. After this point, the three plans begin to diverge. The plan with the largest sample size $n=300$ dominates the others from the consumer point of view since the probability of accepting lots decreases faster as the lot deteriorates in terms of $p$. The shape of the OCC has been extensively analyzed for acceptance sampling in for example Mittag and Rinne (1993, pp. 139-142). Sampling plans that are more favorable either to the consumer or to the producer are constructed altering the values of $n$ and $c$, and if possible the size of the lot $N$. Later in the article, we lay out a procedure for optimizing sampling plans.

\footnotetext{
${ }^{11}$ See Shmueli (2011, chap. 2) for a revision of the OCC in acceptance sampling.
} 


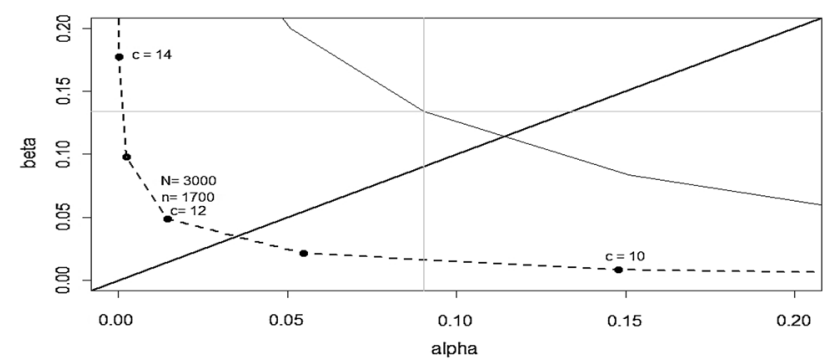

Fig. 10 ROC curve for traditional PL(3000, 1700, c) with $\mathrm{AQL}=0.005$ and $\mathrm{LTPD}=0.010$

\section{The receiver operating characteristics (ROC) curve}

Another useful way of viewing the intricate relationships within the hypergeometric distribution in the context of acceptance sampling is in light of the receiver operating characteristics (ROC) curve, a standard tool in the area of data mining and other computationally intense procedures (Provost and Fawcett 2013, chap. 8). The construction of sampling plans with the help of ROC curves will be very useful for the new procedures suggested later on. is at what rate risk measures change as $c$ changes in a given sampling plan. As cutoff $c$ increases, it becomes more and more difficult to reject lots and therefore producer risk will decrease, but consumer risk increases as more and more lots are accepted. The ROC curve is a quick way of ascertaining this trade off. Table 12 and Fig. 10 show calculations based on the hypergeometric distribution for the sampling plan $P L(3000,1700, c)$ for several values of cutoff $c$. As the cutoff increases in value so does consumer risk and producer risk moves in the opposite direction. For $c=12,13,14$ the producer is in a relatively strong position since his risk is less than the consumer's risk. In Fig. 10, the line coming from the origin shows where $\alpha$ is equal to $\beta$. The risk factor $\alpha$ is less than $\beta$ above this line, indicating plans that favor the producer. At $c=12$, and $\alpha=1.5 \%$ and $\beta=4.8 \%$, one might argue that this plan is optimal for its relatively small cutoff of $c=12$. The ROC curve is an essential ingredient for the arguments that follow.

\section{R Snippets (R Core Team 2014)}

\#Fig. 1 Hypergeometric sampling plan: OCC for PL(3000,200, 0) and LTPD $=0.01$

$\mathrm{N}=3000 ; \mathrm{n}=200 ; \mathrm{c}=0 ; \mathrm{p}=\operatorname{seq}(0, .02, .001) ; \mathrm{LTPD}=.01$

$\mathrm{P}=\operatorname{phyper}\left(\mathrm{c}, \mathrm{p} * \mathrm{~N},(1-\mathrm{p})^{*} \mathrm{~N}, \mathrm{n}\right)$

data.frame $(p, \operatorname{round}(\mathrm{P}, 3))$

$\operatorname{plot}(\mathrm{p}, \mathrm{P}, \mathrm{lty}=1, \mathrm{ylim}=\mathrm{c}(0, .3), \mathrm{xlim}=\mathrm{c}(0, .02)$,

$\mathrm{xlab}=\mathrm{p}=$ percent defective in lot (population)", ylab="P(LTPD) ")

abline $(\mathrm{v}=0.01, \mathrm{~h}=0.125)$

$\operatorname{text}(.006, .25, " \mathrm{OCC} ") ; \operatorname{text}(.0088, .07, " L T P D=0.01 ") ; \operatorname{text}(0.002, .14, " \mathrm{P}(\mathrm{LTPD})=0.125 ")$

\#Fig. 3 ROC curve hypergeometric and binomial sampling plan

$\mathrm{N}=3000 ; \mathrm{n}=1600 ; \mathrm{c}=\mathrm{seq}(0, \mathrm{n}, 1)$

$\mathrm{AQL}=.005$; limalpha $=.05$ \#desired values for producer

LTPD=.01; limbeta=.05 \#desired values for consumer

alpha=1-phyper(c,AQL*N,(1-AQL)*N,n)

beta=phyper(c,LTPD*N,(1-LTPD)*N,n)

$d f=$ round(data.frame(n,c,AQL,LTPD, alpha, beta),3)

$\mathrm{df}[(c<14 \& c>9)$,

alphab=1-pbinom(c,n,AQL) \#binomial approximation

betab=pbinom(c,n, LTPD)

$\mathrm{dfb}=$ round(data.frame( n,c,AQL, LTPD, alphab, betab),3)

$\mathrm{dfb}[(\mathrm{c}<14) \& \mathrm{c}>9$, ]

plot(alpha, beta, xlab="alpha",ylab="beta", xlim=c(0,4*limalpha),ylim=c(0,4*limbeta), Iwd=4)

lines(alpha,beta,Iwd=2,col="black",Ity="dashed");abline(v=limalpha,h=limbeta)

Considering all other variables constant, the ROC curve represents the relationship between $\alpha$ and $\beta$ as the cutoff $c$ assumes different values. ${ }^{12}$ The central question 12 In most cases, the curve is drawn with $(1-\beta)$, the probability of
recognizing a positive occurrence within the universe of all positives.
We use $\beta$, which fits better in our arguments below. Conceptually
nothing has changed. 
\#Table 10 Hypergeometric sampling plans $\mathrm{PL}(\mathrm{N}, \mathrm{n}, \mathrm{c})$ for several lot sizes $\mathrm{N}=3000 ; \mathrm{n}=1400 ; \mathrm{c}=\operatorname{seq}(0, \mathrm{n}, 1)$ \#Lot size and sample size and cutoff values LTPDC=.01; limalphac=.1 \#desired primary values for consumer $\mathrm{AQLC}=.005$; limbetac=.1 \#desired secondary values for consumer betac=1-phyper $(c, A Q L c * N,(1-A Q L c) * N, n)$ alphac=phyper $(c$, LTPDC*N,(1-LTPDC)*N,n) \#plotting Fig. 6 plot $(c$, alphac, $x \lim =c(0,5), y \lim =c(0,1))$; lines $(c$, alphac $)$; lines $(c$, betac $)$ plot(alphac, betac, $x \lim =c(0, .1), y \lim =c(0, .1))$ lines(alphac,betac) $\mathrm{AQLp}=.005$;limalphap=.1 \#desired primary values for producer LTPD $=.01$; limbetap=.1 \#desired secondary values for producer alphap=1-phyper(c,AQLp*N,(1-AQLp)*N,n) betap=phyper(c,LTPDp*N,(1-LTPDp)*N,n) \#plot(c,alphap, xlim=c(0,2*LTPDp*n));lines(c, betap) lines(alphap, betap) $\mathrm{df}=$ round(data.frame $(\mathrm{N}$, n,c,AQLc, LTPDc, alphac, betac,AQLp,LTPDp, alphap,betap,c/n),3) df[alphac $<$ limalphac\&betac $<$ limbetac\&alphac $<$ betac,] df[alphap<limalphap\&betap<limbetap\&alphap<betap,]

\#Fig. 8 Comparing hypergeometric and binomial variances

$\mathrm{f}<-$ function $(\mathrm{n}, \mathrm{N})$ varhb $=(\mathrm{N}-\mathrm{n}) /(\mathrm{N}-1)$

$n=\operatorname{seq}(10,2500$,length.out $=10) ; p=\operatorname{seq}(.01,1$,length.out $=10) ; N=\operatorname{seq}(2500,40000$,length.out $=10)$ varhb<- outer( $n, N, f)$; data.frame( $n, N$, varhb)

$\operatorname{persp}(n, N$, varhb, theta $=40$, phi $=40$, expand $=.71$,

$x \lim =c(00, \max (n)), x l a b=" n=10$ to $2500 "$,

ylim=c(min(N), $\max (N)), y l a b=" N=2500$ to $40000 "$,

zlim=c(min(varhb), $\max (\operatorname{varhb}))$, zlab="1.0 = varh/varb =0.0",

main ="Hypergeometric and binomial variance compared" )

\#Fig. 9 oCC for $P(p) P L(10000, n, d)$

$N=10000 ; p=\operatorname{seq}(0, .035$, length.out=21); $n=100 ; c=1$;

$\mathrm{P} 1=\operatorname{phyper}\left(c,\left(p^{*} N\right),\left((1-p)^{*} N\right), n\right)$

plot(p,P1, pch=1, main="',

ylab="P(x<=c) probability of an acceptable sample-lot",

$x l a b=" p=X / N$ fraction defective in lot", $y \lim =c(0,1))$

lines( $p, P 1$, col="grey")

$\mathrm{n}=200 ; \mathrm{c}=2$

$P 2=\operatorname{phyper}\left(c,\left(p^{*} N\right),\left((1-p)^{*} N\right), n\right)$

points(p,P2,pch=2);lines(p,P2, col="grey")

$\mathrm{n}=300 ; \mathrm{c}=3$

P3=phyper $(c,(p * N),((1-p) * N), n)$

points(p,P3,pch=5);lines(p,P3, col="grey")

legend(.025, .8, c("PL(10000,100,1)", "PL(10000,200,2)", "PL(10000,300,3)"), pch = c(1,2,5)) 
\# Fig. 10 ROC curve for traditional PL(3000, 1700, c) $\mathrm{N}=3000 ; \mathrm{n}=1700 ; \mathrm{c}=\mathrm{seq}(0, \mathrm{n}, 1)$

$\mathrm{AQL}=.005 ;$ limalpha $=.05$ \#desired values for producer $\mathrm{LTPD}=.01 ;$ limbeta $=.05$ \#desired values for consumer alpha=1-phyper(c,AQL*N,(1-AQL)*N,n)

beta $=$ phyper(c,LTPD*N,(1-LTPD)*N,n)

$\mathrm{df}=$ round(data.frame(n,c,AQL,LTPD, alpha, beta),3)

$\operatorname{df}[(c>9 \& c<15)$,

plot(alpha,beta,

xlab="alpha",ylab="beta",

xlim=c $(0,4 *$ limalpha $), y \lim =c(0,4 *$ limbeta $)$,

$\operatorname{lwd}=4)$

lines(alpha,beta,lwd=2,col="black",lty="dashed")

abline $(a=0, b=1,1 w d=2)$

$\operatorname{text}(.021, .08$, paste("N=",N));text(.021,.067, paste("n=",n))

text(.021,.056, paste("c=",df[which.min(sum), ]\$c))

$\operatorname{text}(.01, .18, " \mathrm{c}=14 ")$

$\operatorname{text}(0.15, .02, " \mathrm{c}=10 ")$

alphab=1-pbinom(c,n,AQL)

betab $=$ pbinom $(c, n, L T P D)$

$\mathrm{dfb}=$ round(data.frame( n,c,AQL,LTPD,alphab,betab),3)

lines(alphab,betab)

\section{References}

Associação Brasileira De Normas Técnicas (1989) Planos de amostragem e procedimentos na inspeção por atributos - ABNT NBR 5426:1985, Versão Corrigida (corrected version)

Associação Brasileira De Normas Técnicas (1989) Guia para utilização da norma ABNT NBR 5426 - ABNT NBR 5427:1985 Versão Corrigida (corrected version)

Biedron C, Pagano M, Hedt BL, Kilian A, Ratcliffe A, Mabunda S, Valadez JJ (2010) An assessment of Lot Quality Assurance Sampling to evaluate malaria outcome indicators: extending malaria indicator surveys. Int J Epidemiol 39(1):72-79

Chyu C-C, Yu I-C (2006) A bayesian analysis of the deming cost model with normally distributed sampling data. Qual Eng 18:107-116. doi:10.1080/08982110600567442

Deming WE (1975) On probability as a basis for action. Am Stat 29(4):146-152

Deming WE (1986) Out of the crisis. MIT Press, Cambridge

Dodge HF, Romig HG (1929) Sampling inspection. Bell Syst Tech J 8(4):613-631

Dodge HF, Romig HG (1944) Sampling inspection tables. Wiley, New York

Gelman A (2013) P values and statistical practice. Epidemiology 24(1):69-72. doi:10.1097/EDE.0b013e31827886f7

Gonin HT (1936) The use of factorial moments in the treatment of the hypergeometric distribution and in tests for regression. Philos Mag 7 21:215-226

Guttman I, Wilks SS, Hunter JS (1982) Introductory engineering statistics. Wiley, New York http://www.pubmedcentral.nih.gov/articlerender.fcgi?artid=2710509 \&tool $=$ pmcentrez\&rendertype $=$ abstract

Hund L (2014) New tools for evaluating LQAS survey designs. Emerg Themes Epidemiol 11:2. doi:10.1186/1742-7622-11-2

Iso-International Standard 2859-1 (1999) Sampling procedures for inspection by attributes-Part 1: sampling schemes indexed by acceptance quality limit (AQL) for lot-by-lot inspection, 2nd edn

Iso-International Standard 2859-2 (1985) Sampling procedures for inspection by attributes-Part 2: sampling plans indexed by limiting quality (LQ) for isolated lot inspection, 1st edn

Mittag HJ, Rinne H (1993) Statistical methods of quality assurance, 3rd edn. Chapman \& Hall, New York

Neyman J, Pearson E (1933) On the problem of the most efficient tests of statistical hypotheses. Philos Trans R Soc A Math Phys Eng Sci 231:694-706

NIST/SEMATECH (2012) e-handbook of statistical methods. http:// www.itl.nist.gov/div898/handbook/

Pagano M, Valadez JJ (2010) Commentary: understanding practical lot quality assurance sampling. Int J Epidemiol 39(1):69-71. doi:10.1093/ije/dyp406

Provost F, Fawcett T (2013) Data science and business. O'Reilly, Cambridge

R Core Team (2014) R: a language and environment for statistical computing. R Foundation for Statistical Computing, Vienna, Austria. http://www.R-project.org/

Rhoda DA, Fernandez SA, Fitch DJ, Lemeshow S (2010) LQAS: user beware. Int J Epidemiol 39(1):60-68. doi:10.1093/ije/dyn366

Rice J (1995) Mathematical statistics and data analysis, 2nd edn. Duxbury Press, Belmont

Rstudio Inc (2013) shiny: web application, framework for R. R package [Version 0.5.0]. http://CRAN.R-project.org/package= shiny

Samohyl R (2013) Audits and logistic regression, deciding what really matters in service processes. A case study of a government funding agency for research grants. In: Proceedings of the Fourth International Workshop on knowledge discovery, knowledge management, and decision support. doi:10.2991/.2013.33

Samohyl R (2015) An acceptance sampling approach to polling public opinion. https://www.researchgate.net/publication/ 295919947

Samohyl R (2016) Lot quality assurance sampling (LQAS) from a Neyman-Pearson perspective https://www.researchgate.net/pub lication/305334204

Schilling EG, Neubauer DV (2009) Acceptance sampling in quality control, 2nd edn. CRC Press, Boca Raton

Shmueli G (2011) Practical acceptance sampling, 2nd ed. CreateSpace Independent Publishing Platform

Squeglia NL (1994) Zero acceptance number sampling plans. ASQ Quality Press, Milwaukee

Suresh K, Sangeetha V (2011) Construction and selection of bayesian chain sampling plan (BChSP-1) using quality regions. Modern Appl Sci 5(2):226-234. doi:10.5539/mas.v5n2p226 